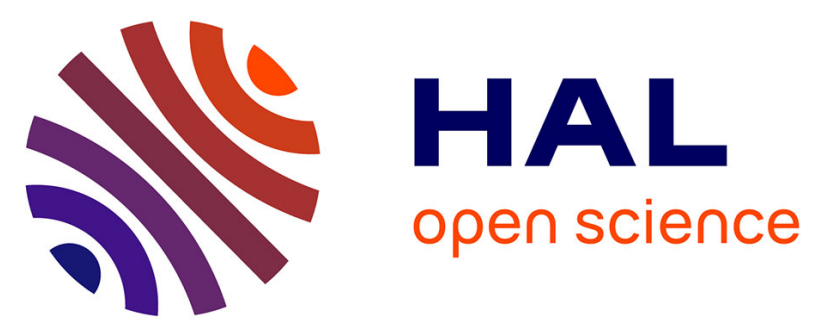

\title{
Deposition of binder-free oxygen-vacancies NiCo2O4 based films with hollow microspheres via solution precursor thermal spray for supercapacitors
}

Yangzhou Ma, Zexin Yu, Meimei Liu, Chen Song, Xuanning Huang, Michel Moliere, Guangsheng Song, Hanlin Liao

\section{To cite this version:}

Yangzhou Ma, Zexin Yu, Meimei Liu, Chen Song, Xuanning Huang, et al.. Deposition of binder-free oxygen-vacancies $\mathrm{NiCo} 2 \mathrm{O} 4$ based films with hollow microspheres via solution precursor thermal spray for supercapacitors. Ceramics International, 2019, 45, pp.10722 - 10732. 10.1016/j.ceramint.2019.02.145 . hal-03485871

\section{HAL Id: hal-03485871 \\ https://hal.science/hal-03485871}

Submitted on 20 Dec 2021

HAL is a multi-disciplinary open access archive for the deposit and dissemination of scientific research documents, whether they are published or not. The documents may come from teaching and research institutions in France or abroad, or from public or private research centers.
L'archive ouverte pluridisciplinaire HAL, est destinée au dépôt et à la diffusion de documents scientifiques de niveau recherche, publiés ou non, émanant des établissements d'enseignement et de recherche français ou étrangers, des laboratoires publics ou privés.

\section{(ㄷ)(1) $\$$}

Distributed under a Creative Commons Attribution - NonCommerciall 4.0 International 
Version of Record: https://www.sciencedirect.com/science/article/pii/S0272884219304419

Manuscript_ab93aedb32bfa7b998a38ec269a499be

\title{
Deposition of binder-free oxygen-vacancies $\mathrm{NiCo}_{2} \mathrm{O}_{4}$ based films with hollow microspheres via solution precursor thermal spray for supercapacitors
}

\author{
Yangzhou MA ${ }^{\mathrm{a}, \mathrm{b}, 1}$, Zexin $\mathrm{YU}^{\mathrm{b}, 1, *}$, Meimei $\mathrm{LIU}^{\mathrm{b}}$, Chen $\mathrm{SONG}^{\mathrm{b}, \mathrm{c}}$, Xuanning HUANG ${ }^{\mathrm{a}}$, Michel \\ MOLIERE $^{\mathrm{b}}$, Guangsheng $\mathrm{SONG}^{\mathrm{a}}$, Hanlin LIAO $^{\mathrm{b}}$
}

a School of Materials Science and Engineering, Anhui University of Technology, Ma'anshan 243002, PR China

b ICB-LERMPS UMR 6303, CNRS, UTBM, Université de Bourgogne Franche-Comté, 90010 Belfort, France.

${ }^{c}$ Guangdong Institute of New Materials, National Engineering Laboratory for Modern Materials Surface Engineering Technology, Guangzhou 510651, China

*Corresponding author. E-mail address: zexin.yu@utbm.fr (Zexin Yu),

1: these authors contributed equally to this work

\begin{abstract}
Hollow micro-/nanostructures and oxygen vacancies are highly desirable for supercapacitors due to high active surface area and outstanding electrochemical properties. In order to benefiting from the both effect, binder-free oxygen-vacancies $\mathrm{NiCO}_{2} \mathrm{O}_{4}$ based films with hollow microspheres were pioneering directly deposited via one kind thermal spray technology novel coating technologies, named solution precursor thermal spray (SPTS) process. To our best knowledge, the rapid one-step SPTS route was firstly employed to synthesize and deposit $\mathrm{NiCo}_{2} \mathrm{O}_{4}$ films for supercapacitor applications. The CV data clearly demonstrated that the specific capacitances of more oxygendeficient $\mathrm{NiCo}_{2} \mathrm{O}_{4}$ electrodes with hollow microspheres (i.e. F12) are significant higher than that of
\end{abstract}


$\mathrm{NiCo}_{2} \mathrm{O}_{4}$ films composed by solid particles (i.e. P12) with less oxygen vacancies, exhibiting a rapid increment of about 20 times. The oxygen-vacancies $\mathrm{NiCo}_{2} \mathrm{O}_{4}$ film composed of hollow spheres possesses large specific capacitance of $902 \mathrm{~F} / \mathrm{g}$ at the current density of $1 \mathrm{~A} / \mathrm{g}$ with a good capacitance retention of $89.2 \%$ after 2500 cycles under $20 \mathrm{mV} / \mathrm{s}$ scan rate and a quite small resistance. Furthermore, this work pointed out that the Solution Precursor Thermal Spray (SPTS) route with highinterest for depositing other binder-free metal oxides based films as electrodes for other energy storage applications, benefiting from suitable surface morphologies and in-situ introduced oxygen vacancies as well.

Keywords: Solution precursor thermal spray; $\mathrm{NiCo}_{2} \mathrm{O}_{4}$ film; binder-free; hollow microspheres; oxygen vacancies; supercapacitor 


\section{Introduction}

To better utilize the renewable energy, various potential energy storage and conversion devices have been developed, include Lithium-ion batteries (LIBs), supercapacitors and fuel cells [1-4]. Especially, supercapacitors are the one of the most attractive in the research, attributed to their higher power density than batteries and higher energy density than traditional capacitors [5-9]. Binary metal oxides are featured with relative higher specific capacitance, better structure stability and electric conductivity, and are considered to possess both their advantages. Among different binary transition metal oxides, nickel cobaltite $\left(\mathrm{NiCo}_{2} \mathrm{O}_{4}\right)$ is having one of the most success in supercapacitors applications [10]. $\mathrm{NiCo}_{2} \mathrm{O}_{4}$ not only benefits from its wonderful electrical conductivity and superior electrochemical activity but also has some advantages such as low cost, natural abundance, environmental safety and low toxicity $[10,11]$.

Nevertheless, it is reported that $\mathrm{NiCo}_{2} \mathrm{O}_{4}$ still suffers from low capacitance and poor rate performance due to their high dependence on surface faradaic redox reactions and ion diffusion. To improve the aforementioned performances, usage of hollow metal oxide microstructures is one of most attractive solution strategies. It was reported the hollow micro-/nanostructured architectures with high surface area would not only supply more electrochemical sites to increase the capacitance, but also significantly enhance ion diffusion with shortened pathway to improve the rate performance $[12,13]$. Moreover, introduce of oxygen vacancies was believed to improve electrochemical properties in many application fields, such as electrical water splitting and supercapacitors $[14,15]$. Thanks to the formation of oxygen vacancies, it will enhance the diffusion for charge carriers, adsorption of $\mathrm{OH}^{-}$and serve as active sites for redox reactions $[16,17]$. It could be easily inferred that combination of the two strategies will further improve the supercapacitor performances. However, NiCo2O4 benefiting from the synergistic effect of oxygen vacancy and hollow microspheres were rarely reported. In addition, up to now, wet-chemical routes as main candidate, such as hydrothermal/solvothermal [18], precipitation [19], sol-gel [20], have been tried for preparing $\mathrm{NiCo}_{2} \mathrm{O}_{4}$ materials as electrodes. They are suitable for adjusting morphologies and introducing oxygen vacancies by some extra treatments, 
but some limitations were still observed, including time-consuming and multiple-steps. Moreover, from the $\mathrm{NiCo}_{2} \mathrm{O}_{4}$ nanopowder to prepare the final electrodes, the usage of binder would also hinder the transportation of electrons and the diffusion of ions and damage the stability of electrical performances [21-23].

Therefore, in this work, the oxygen-vacancies microspheres composed $\mathrm{NiCo}_{2} \mathrm{O}_{4}$ electrodes will be prepared. Besides, a novel rapid fabrication route featured with one-step and binder-free will be also employed, called as Solution Precursor Thermal Spray (SPTS) technology. In the SPTS route, the injected precursor solutions as feedstock would be heated and accelerated by different heat sources to stack-up and directly form the final films [15, 24]. Herein, both the direct-current (DC) plasma and oxyacetylene flame were employed as heat sources with different spray torches, corresponding to the Solution Precursor Plasma Spray (SPPS) and Solution Precursor Flame Spray (SPFS) routes. During the deposition via SPPS and SPFS route, the feeding precursor solution droplets went through a series of physical and chemical processes, including break-up and evaporation, precipitation, pyrolysis and crystallization [25]. It should be noted that the whole duration of depositing suitable metal oxide films was within several minutes without binders. It will not only present the significance of scientific research but also will bring potential industrial prospects. The solution precursor flame spraying (SPFS) possess a high working temperature $\left(>3000^{\circ} \mathrm{C}\right)$ and a large cooling rate $\left(>10^{\wedge} 3 \mathrm{~K} / \mathrm{s}\right)$, as well as a reducing acetylene as working gas $[26,27]$. Similar with our previous studies about oxygendefective $\mathrm{ZnO}$ [28], thanks to the type non-equilibrium feature route and usage of reducing gas, oxygen vacancies are capable to be in-situ introduced into $\mathrm{NiCo} 2 \mathrm{O} 4$ films during deposition procedures without any post-treatments.

Moreover, to our best knowledge, the $\mathrm{NiCo}_{2} \mathrm{O}_{4}$ films deposited by SPFS and SPPS routes for supercapacitors have not been reported yet. Oxygen-deficient $\mathrm{NiCo}_{2} \mathrm{O}_{4}$ films composed of hollow microspheres were also firstly prepared. The characterization of these $\mathrm{NiCo}_{2} \mathrm{O}_{4}$ films in terms of microstructures and compositions were conducted by SEM, GIXRD (grazing-incidence X-ray diffraction) XRD, Raman and XPS analyses. The oxygen-deficient $\mathrm{NiCo}_{2} \mathrm{O}_{4}$ microspheres films as 
electrodes exhibit good capacitance $(902 \mathrm{~F} / \mathrm{g}$ at a current density of $1 \mathrm{~A} / \mathrm{g})$ and excellent cycling stability (89.2\% capacitance retention after 2500 cycles under $20 \mathrm{mV} / \mathrm{s}$ scan rate).

\section{Experimental section}

\subsection{Preparation of precursor solution}

Nickel(II) nitrate hexahydrate $\left(\mathrm{Ni}\left(\mathrm{NO}_{3}\right)_{2} \cdot 6 \mathrm{H}_{2} \mathrm{O}\right.$, Alfa Aesar, 98\%) and Cobalt(II) nitrate hexahydrate $\left(\mathrm{Co}\left(\mathrm{NO}_{3}\right)_{2} \cdot 6 \mathrm{H}_{2} \mathrm{O}\right.$, Alfa Aesar, ACS, 98.0-102.0\%) were chosen as the solutes to prepare the corresponding precursor solutions. Considering the different deposition efficiency of $\mathrm{Ni}\left(\mathrm{NO}_{3}\right)_{2}$ and $\mathrm{Co}\left(\mathrm{NO}_{3}\right)_{2}$ solutions in the SPPS and SPFS process, the stoichiometric ratio of the two kind metal salts could not be the suitable condition for synthesizing the desired $\mathrm{NiCo}_{2} \mathrm{O}_{4}$ phase. Therefore, various compositional ratios of $\mathrm{Ni} / \mathrm{Co}$ in mole were employed in the precursor solutions, including $0.25,0.5$ and 1 , respectively for both the SPPS and SPFS process. The concentration of $\mathrm{Co}\left(\mathrm{NO}_{3}\right)_{2}$ is a constant as $0.16 \mathrm{M}$. Based on the different deposition technology and various precursor solutions, the samples were named as P14, P12, P11 and F11, F12 and F14. In the sample name, P is on behalf of solution precursor plasma spray (SPPS) process, and F is on behalf of solution precursor flame spray (SPFS) process. The number in the sample name stands for the concentration ratio between $\mathrm{Ni}\left(\mathrm{NO}_{3}\right)_{2}$ and $\mathrm{Co}\left(\mathrm{NO}_{3}\right)_{2}$. In all the deposition films, the concentration of $\mathrm{Co}\left(\mathrm{NO}_{3}\right)_{2}$ is $0.16 \mathrm{M}$ as constant. For example, 12 means concentration ratio of $\mathrm{Ni}\left(\mathrm{NO}_{3}\right)_{2}: \mathrm{Co}\left(\mathrm{NO}_{3}\right)_{2}$ equals to $1: 2$, indicating the concentration of $\mathrm{Ni}\left(\mathrm{NO}_{3}\right)_{2}$ and $\mathrm{Co}(\mathrm{NO} 3) 2$ are $0.08 \mathrm{M}$ and $0.16 \mathrm{M}$, respectively. All the parameters of solution precursor can be found in Table 1. In order to promote the in-suit synthesis of $\mathrm{NiCo}_{2} \mathrm{O}_{4}$ phase from the $\mathrm{Ni}\left(\mathrm{NO}_{3}\right)_{2}$ and $\mathrm{Co}\left(\mathrm{NO}_{3}\right)_{2}$ solutions during the SPPS and SPFS process, employing ethanol as solvent would supply more heat energy for the in-suit synthesis of $\mathrm{NiCo}_{2} \mathrm{O}_{4}$ phase from solution precursors. While, due to the limited solubility of $\mathrm{Ni}\left(\mathrm{NO}_{3}\right)_{2}$ and $\mathrm{Co}\left(\mathrm{NO}_{3}\right)_{2}$ in pure ethanol, a certain amount of water was inevitable in the solvent. Therefore, mixture of ethanol and water is preferred to be used as the suitable solvent. 


\subsection{Deposition experiments}

The F4 direct current (DC) plasma torch (OerlikonMetco, Switzerland) was utilized as the heat source for the SPPS process with a $6 \mathrm{~mm}$ internal diameter (ID). The as-prepared solutions were radially driven by pressured nitrogen into the plasma plume along the radial direction through a stainless steel injector. The the relative axial and radical distance and angle between injector and nozzle is well controlled by a homemade-device. The other plasma spraying parameters, such as the flow rates of primary gas (Ar), secondary gas $\left(\mathrm{H}_{2}\right)$, current and deposition cycles, were kept constant. The corresponding schematic diagram of SPPS process is illustrated in Fig. 1a.

For the SPFS route, a flame torch (Eutectic-CastolinCastodyn 8000 powder flame spray gun) is generated by oxygen $\left(\mathrm{O}_{2}\right)$ and acetylene $\left(\mathrm{C}_{2} \mathrm{H}_{2}\right)$. The solution precursors were axially feed into the flame jet, driven by pressured nitrogen as well. The smallest inner diameter of the stainless steel injector is $0.26 \mathrm{~mm}$. The injector is along the central line of flame spray gun and the tip of injector is about $2 \mathrm{~mm}$ up-stream compared to the nozzle of flame torch along axial direction. The solution flow rates were mainly controlled by using different pressures of $\mathrm{N}_{2}$ gas. The schematic diagram of SPFS process is illustrated in Fig. $1 \mathrm{~b}$ as well.

The commercial Ni plates with thickness of $1.5 \mathrm{~mm}$ are selected as substrates, in which the efficient deposition area is $10 \mathrm{~mm} * 10 \mathrm{~mm}$. Both the plasma torch and flame torch were mounted on a robotic arm (ABB, Switzerland) to control the moving trajectory and velocity for depositing films, which scans horizontally and vertically across the substrate. 8 scans were employed to build-up final metal oxide films. Table 1 summarized the corresponding spraying details of $\mathrm{NiCo}_{2} \mathrm{O}_{4}$ related films by SPPS and SPFS routes.

\subsection{Characterization of the films}

The surface morphologies of the $\mathrm{NiCO}_{2} \mathrm{O} 4$ related films were examined by scanning electron microscopy (SEM, JEOL, JSM-5800LV). The compositions of as-deposited films were determined by 
grazing-incidence X-ray diffraction (GIXRD, SmartLab, Rigaku, Japan) using a copper anticathode with a scanning speed of $4 \% \mathrm{~min}$ and an incident angle of $4^{\circ}$ X ray diffraction (XRD, Bruker AXS D8 foeus, Germany) using cobalt anticathode $\left(\lambda=1.78897 \AA\right.$ ) with a seanning speed of $0.1^{\circ} / \mathrm{s}$ and Raman spectrum (XploRA PLUS Raman Microscope, Horiba Jobin Yvon) with the excitation occurring at $532 \mathrm{~nm}$. The X-ray photoelectron spectroscopy (XPS, Thermo K-Alpha+) with Al Ka radiation source $(1486.6 \mathrm{eV})$ was performed to examine the composition and metal oxidation states of the sample. All the binding energies were calibrated by using the contaminant carbon (C 1s) $284.6 \mathrm{eV}$ as a reference. The adhesion of films was evaluated by a scratch tester (Revetest ${ }^{\circledR}$ RST $^{3}$, Anton Pear GmbH) equipped with a Rockwell diamond indenter having a tip radius of $0.2 \mathrm{~mm}$. The scratches were linear with progressively increasing load. The final load is $15 \mathrm{~N}$ and the length of scratch was $5 \mathrm{~mm}$. Since the SPTS-deposited $\mathrm{NiCo}_{2} \mathrm{O}_{4}$ films were porous, the critical load should be defined at the onset of the films loss associated with the beginning of visibility of metallic substrate inside the scratch channel. This criterion is based on previous publications on suspension plasma spray (SPS) coatings [29, 30]. These measurements would be with the help of optical microscope.

\subsection{Electrochemical measurements}

The electrochemical measurements were performed on Zahner electrochemical workstation (Zenium E) via three-electrode system with a working electrode (WE), a reference electrode (RE) and a counter electrode (CE). The RE and CE were SCE (saturated calomel electrode) and Platinum plate electrode $(1 \mathrm{~cm} * 1 \mathrm{~cm})$. The WE was processed to a $3 \times 1 \mathrm{~cm}$ sheet with $1 \times 1 \mathrm{~cm}$ active materials. A $2 \mathrm{~mol} / \mathrm{L} \mathrm{KOH}$ solution served as the electrolyte at room temperature [31]. Cyclic voltammetry (CV) curves were recorded between $-0.1 \mathrm{~V}$ and $0.5 \mathrm{~V}$ at various scan rates ranging from 5 to $200 \mathrm{mV} / \mathrm{s}$. Galvanostatic charge/discharge (GCD) test was conducted between 0 and $0.5 \mathrm{~V}$ at different current densities from 0.5 to $20 \mathrm{~A} / \mathrm{g}$. The electrochemical impedance spectroscopy (EIS) measurements were performed by applying an $\mathrm{AC}$ voltage with $5 \mathrm{mV}$ amplitude in a frequency range from $0.01 \mathrm{~Hz}$ to $100 \mathrm{kHz}$. The 
specific capacitances of the active materials were calculated from $\mathrm{CV}$ and galvanostatic charge/discharge curves respectively according to the equation (1) [32, 33] and equation (2) [34, 35]:

$$
\begin{gathered}
\mathrm{C}=\frac{\mathrm{A}}{\mathrm{m} \times \Delta \mathrm{V} \times \mathrm{v}} \\
\mathrm{C}=\frac{\mathrm{I} \times \Delta \mathrm{t}}{\mathrm{m} \times \Delta \mathrm{V}}
\end{gathered}
$$

where $\mathrm{A}$ is the integrated area of $\mathrm{CV}$ curve in one cycle, $v$ is the scan rate, $I$ is the constant charge/discharge current, $\Delta t$ is the charge/discharge time, $\Delta V$ is the potential window, and $m$ is the average mass of $\mathrm{NiCo}_{2} \mathrm{O}_{4}$ ( around $1.0 \mathrm{mg}$ in this investigation) in the WE. Meanwhile, the cycle-life of the supercapacitors could be evaluated by the CV tests through certain cycles [36-38]

\section{Results and discussions}

\subsection{Composition of $\mathrm{NiCo}_{2} \mathrm{O}_{4}$ films via SPPS and SPFS routes}

In order to confirm the composition of these composite films, the use of XRD patterns grazingincidence X-ray diffraction (GIXRD) were firstly used. Since the thin film (about $5 \mu \mathrm{m}$ ) is hard to be peeled off from Ni substrate, the as-prepared samples with substrates were directly tested by GIXRD. The corresponding GIXRD patterns were illustrated in Fig.2. Due to the thin thickness and porous surface morphologies, the underlying Ni substrate (PDF card No. 01-1260) was also detected. Firstly, the characteristic peak of $\mathrm{NiCo}_{2} \mathrm{O}_{4}$ phase (PDF card No. 73-1702) were observed in the all the GIXRD patterns, indicating the successful synthesis of $\mathrm{NiCO}_{2} \mathrm{O}_{4}$ phase. This is point would be further confirmed by Raman and XPS spectrum. Owing to the incomplete synthesis reactions and oxidation of Ni substrate during deposition, the extra $\mathrm{Co}_{3} \mathrm{O}_{4}$ (PDF card No. 43-1003) and NiO (PDF card No. 780423) phases were also detected in the films. Among all the GIXRD patterns, the peaks of $\mathrm{NiCo}_{2} \mathrm{O}_{4}$ are more intensive than those of $\mathrm{Co}_{3} \mathrm{O}_{4}$ and $\mathrm{NiO}$ phases, suggesting higher content of $\mathrm{NiCO}_{2} \mathrm{O}_{4}$ phase in all the films. In addition, as shown in Fig. 2a-c, more intensive $\mathrm{NiCo}_{2} \mathrm{O}_{4}, \mathrm{NiO}$ and $\mathrm{Co}_{3} \mathrm{O}_{4}$ peaks were observed compared to the SPFS-deposited samples. This might be ascribed to two causes, including (1) higher deposition efficiency and (2) better synthesis of metal oxides from the solution 
precursors in the SPPS route, thanks to the higher temperature of plasma plume than that of oxyacetylene flame in SPFS method.

Besides, it is clear that a peak at $43.28^{\circ}$ (as marked by heat sharps) were all detected in the SPPSdeposited films as shown in Fig. 2a-c, assigning to $\mathrm{NiO}$ phase. By contrast, no characteristic $\mathrm{NiO}$ peaks were detected in the SPFS-deposited samples. Therefore, high ratio of NiO was obtained in P11, P12 and P14 samples. Considering higher temperature of plasma plume than oxyacetylene flame, the observed $\mathrm{NiO}$ phase in the SPPS-deposited films could be related to the more serious oxidation of $\mathrm{Ni}$ substrate, since the $\mathrm{NiO}$ peak was always observed from different $\mathrm{Ni} / \mathrm{Co}$ ratio of raw precursor solutions. Furthermore, the magnified curves ranging $40^{\circ}-50^{\circ}$ were illustrated as the inset pictures in Fig. 2a-f. On the one hand, for the SPPS-deposited films, the most intensive peak was only corresponding to $\mathrm{Ni}$ phase. Therefore, the strongest peak for $\mathrm{NiCo}_{2} \mathrm{O}_{4}$ phase was at $36.71^{\circ}$ in the SPFS-deposited samples, corresponding to the (311) crystal plane. On the other hand, it was obvious that the most intensive peaks at around $45^{\circ}$ in the SPPS-deposited films were indeed composed by several peaks, including $\mathrm{Ni}, \mathrm{NiCO}_{2} \mathrm{O}_{4}$ and $\mathrm{Co}_{3} \mathrm{O}_{4}$ phases (as illustrated in inset pictures of Fig. 2a-c). As such, in the SPP-deposited films, the strongest peak for $\mathrm{NiCo}_{2} \mathrm{O}_{4}$ phase is at $44.64^{\circ}$, indicating the (004) crystal plane. It should be noted that the strongest peak of $\mathrm{NiCo}_{2} \mathrm{O}_{4}$ in the standard $\mathrm{XRD}$ pattern (PDF card No. 73-1702) was (311) crystal plane. Therefore, the relative preferential orientation of $\mathrm{NiCo}_{2} \mathrm{O}_{4}$ along (004) plane in the SPPS-deposited films should be related to the formation of flakelike particles, which is agreement with the previous publication [39].

However, due to the thinness of the films, the Ni substrate (PDF card No. 01 1260) exhibited more intensive peaks than these of the films, leading to a difficulty in detecting the phases of the resultant materials in the samples produced by the SPPS process. The examples of the XRD patterns for the $\mathrm{NiC}_{2} \mathrm{O}_{4}$ related samples via the SPPS and SPFS routes can be seen in Fig. 2 and Fig.3, respectively. The desired $\mathrm{NiCo}_{2} \mathrm{O}_{4}$ phase (PDF card No. 73-1702) was observed in all the samples. It is clear that the intensity of the film compositions (i.e. $\mathrm{NiCo}_{2} \mathrm{O}_{4}$ ) in SPPS-deposited films is higher than that of the SPFS deposited films. This might be ascribed to two causes, including (1) higher deposition efficiency and (2) better synthesis of those metal oxides from the solution precursors in the SPPS process, thanks 
to the higher heating temperature in the plasma torch. Secondly, especially in terms of the $\mathrm{NiCo}_{2} \mathrm{O}_{4}-$ composite films via the SPPS technology, the phase compositions of the resultant films from the different solution precursors were different, as shown in Fig. 2ac. Under the condition of a lower $\mathrm{Ni} / \mathrm{Co}$ ratio, extra $\mathrm{Ce}_{3} \mathrm{O}_{4}$ (PDF card No. 43-1003) was detected (see Fig. 3a). In addition, the marked $\mathrm{NiO}$ phase in the $\mathrm{NiC}_{2} \mathrm{O}_{4}$-composite samples might have been generated via two methods: on the one hand, the $\mathrm{Ni}\left(\mathrm{NO}_{3}\right)$ z might have been transferred to the $\mathrm{NiO}$ phase by pyrolysis and decompesition in the plasma plume; on the other hand, due to the high temperature of the plasma plume and flame flow and of the substrate during depesition, the $\mathrm{Ni}$ plate substrates might have oxidized to become the $\mathrm{NiO}$ phase.

In order to further confirm the composition of the above samples, the Raman spectra of those $\mathrm{NiCo}_{2} \mathrm{O}_{4}$ -composite films deposited by the SPPS and SPFS processes are illustrated in Fig. 34 . The peaks at $187,478,525,649 \mathrm{~cm}^{-1}$ can be assigned to the $\mathrm{NiCo}_{2} \mathrm{O}_{4}$ phase [40-42], which were observed in all these samples. The $\mathrm{Co}_{3} \mathrm{O}_{4}$ phase demonstrates characteristic peaks at 191 and $675 \mathrm{~cm}^{-1}$ [43, 44], exhibiting in the $\mathrm{P} 14-\mathrm{NiCo}_{2} \mathrm{O}_{4}, \mathrm{P} 12-\mathrm{NiCe}_{2} \mathrm{O}_{4}$ and $\mathrm{F} 14-\mathrm{NiCe}_{2} \mathrm{O}_{4}$ samples. In addition, the extra $\mathrm{NiO}$ phase was detected in the $\mathrm{P} 11-\mathrm{NiC}_{2} \Theta_{4}, \mathrm{~F} 12 \mathrm{NiC}_{2} \Theta_{4}$ and $\mathrm{F} 11-\mathrm{NiC}_{2} \mathrm{O}_{4}$ samples with peaks at either $505[45,46]$ or $546 \mathrm{~cm}^{-1}[47,48]$ as produced by the SPPS or SPFS processes, respectively. Based on previous studies, the peaks at 505 or $546 \mathrm{~cm}^{-1}$ both corresponded to the longitudinal optical (LO) mode of $\mathrm{NiO}$ [45-47]. The different positions of the $\mathrm{LO}$ mode in the $\mathrm{NiO}$ phase should relate to the two deposition technologies. It was reported that the LO mode (at $546 \mathrm{~cm}^{-1}$ ) derived from paritybreaking imperfection, due to the high nickel-vacancy concentration [47]. For the SPFS process, due to the direct usage of oxygen as the working gas for the flame torch, it was easier to form nickel vacancies via SPFS technology than the SPPS route. By contrast, in the SPPS process, owing to the existence of reduced $\mathrm{H}_{2}$ and non-equilibrium feature, oxygen vacancies would be introduced as reported in our previous work [28]. Furthermore, taking $\mathrm{P} 12 \mathrm{NiC}_{2} \mathrm{O}_{4}$ and $\mathrm{F} 12 \mathrm{NiCe}_{2} \mathrm{\Theta}_{4}-$ as comparisons, using the same $\mathrm{Ni} / \mathrm{Co}$ stoichiometric ratio in the raw solutions, the extra phase in the $\mathrm{P} 12 \mathrm{NiC}_{2} \mathrm{O}_{4}$-sample was $\mathrm{C}_{3} \mathrm{O}_{4}$, while the extra-compesition for $\mathrm{F} 12 \mathrm{NiC}{ }_{2} \Theta_{4}-$ was $\mathrm{NiO}$. This demonstrated that the SPPS process exhibited higher deposition efficiency of the Co-solution, while 
the SPFS route promoted greater deposition of the $\mathrm{Ni}$ solution, which might have been due to the different injection directions and spraying torches used in each. Besides, P12 and F12 sample were taken for comparisons, since the raw precursor solutions were with the stoichiometric $\mathrm{Ni} / \mathrm{Co}$ ratio for $\mathrm{NiCo}_{2} \mathrm{O}_{4}$ phase. From both the XRD and Raman results (as shown in Fig. $2 b$ and Fig. $3 b$ ), the extra $\mathrm{Co}_{3} \mathrm{O}_{4}$ phase was observed in the $\mathrm{P} 12$ sample, indicating higher deposition efficiency of the Co solution from the SPPS route. This due to the different injection directions and spraying torches between SPPS and SPFS technologies.

Moreover, the P12 and F12 samples were selected to do the further XPS analysis due the deposition from stoichiometric ratio in the raw precursor solutions, aiming to have a clear understanding on the composition and oxidation of the metals present in $\mathrm{NiCO}_{2} \mathrm{O}_{4}$ sample, as shown in Fig. 4 5. Survey spectrum spectra are shown in Fig. 45 (a) and (e), which shows the presence of $\mathrm{Ni}, \mathrm{Co}, \mathrm{C}$, and $\mathrm{O}$ and the absence of any other impurities. The detected C 1 s peak at $284.6 \mathrm{eV}$ can be assigned to carbon contamination and $\mathrm{CO}_{2}$ adsorbed on the surface of the film. High-resolution spectra of $\mathrm{Ni} 2 \mathrm{p}$ can be fitted with two spin-orbit doublets and two shakeup satellite peaks (indicated as "Sat."). These two spin-orbit doublets are of $\mathrm{Ni}^{2+}$ and $\mathrm{Ni}^{3+}$, and the two shakeup satellite peaks are assigned Fig. 4(b) 5(b) and (f). In particular, the fitting peaks at 853.1 and $870.6 \mathrm{eV}$ are indexed to $\mathrm{Ni}^{2+}$, and those centered at 855.3 and $873.5 \mathrm{eV}$ can be indexed to $\mathrm{Ni}^{3+}$, which is agreement with previous study [49, 50]. In a similar way, Co $2 \mathrm{p}$ is also fitted, the doublet peaks at binding energies of 779.1 and $794.7 \mathrm{eV}$ are assigned to $\mathrm{Co}^{3+}$, and peaks at 780.6and $796.6 \mathrm{eV}$ are due to $\mathrm{Co}^{2+}$ species ( Fig. $4 \mathrm{c} 5 \mathrm{c}$ and $4 \mathrm{~g} 5 \mathrm{~g}$ ) [49, 50]. The XPS results indicate that sample contains $\mathrm{Ni}^{2+} / \mathrm{Ni}^{3+}$ and at the same time $\mathrm{Co}^{2+} / \mathrm{Co}^{3+}$, which is agreement with the previous studies on $\mathrm{NiCo}_{2} \mathrm{O}_{4} / \mathrm{NiO}$ composite $[49,50]$. In addition, the highresolution spectrum for the $\mathrm{O}$ 1s region (Fig. 4d 5d and Fig. 4h 5h) includes three oxygen peaks, including OI $(529.5 \mathrm{eV})$, OII $(531.1 \mathrm{eV})$ and OIII $(532.5 \mathrm{eV})$. The OI and OIII peaks associated to oxygen atoms bound to metals and hydroxyl species of surface-adsorbed water molecules $[13,14,51]$. And the obvious OII peak located at $531.1 \mathrm{eV}$ attributes to considerable defect sites with low oxygen coordination bond, which indicates a big amount of oxygen defect existing in the SPFS sample [13, 14, 51]. Comparing Fig. 4h 5h with Fig. 4d 5d, more obvious OII peak was observed in F12 sample. The 
area ratio of OI, OII and OIII peaks for P12 and F12 samples were listed in Table S1. It is also clear that the OII in F12 sample takes up more proportion than the P12 film. Therefore, it indicates that more oxygen-vacancies were in-situ introduced in the SPFS-deposited films.

\subsection{Characterization of surface morphologies}

For the nickel cobaltite-related samples via the SPPS or SPFS processes, their surface morphologies were characterized by SEM, as shown in Fig. 5 6. Firstly, the $\mathrm{NiCo}_{2} \mathrm{O}_{4}$-composite films deposited by the SPPS process exhibited more uniformity than those prepared via the SPFS method. The greater inter-porosity between each agglomerated part should be more favorable for supercapacitor application, since more electrolytes could be stored on the surface of these electrodes via SPPS routes. Among the P14, P12 and P11 samples, it was clear that each agglomerated part was composed of submicron or nano-sized solid particles, as shown in Fig. 6 5b, d and f, respectively. In terms of the SPPS-deposited samples, with the increment of the $\mathrm{Ni} / \mathrm{Co}$ ratio in the solution precursors, the dimensions of each of the composed particles diminished, from around $220 \mathrm{~nm}$ to approximately 130 $\mathrm{nm}$, respectively, with $50 \mathrm{~nm}$ as the approximate mean size. In particular, flake-shaped nanostructures were observed in the P14 and P12 samples as illustrated in Fig. 6 5b and d. From the P14 4 to P12 and P11 samples, more of the $\mathrm{Ni}\left(\mathrm{NO}_{3}\right)_{2}$ and $\mathrm{Co}\left(\mathrm{NO}_{3}\right)_{2}$ solutions needed to be injected in order to facilitate the three reactions (reactions (i), (ii) and (iii)) to synthesize the $\mathrm{NiCO}_{2} \mathrm{O}_{4}, \mathrm{Co}_{3} \mathrm{O}_{4}$ and $\mathrm{NiO}$ phases, suggesting more energy was consumed for pyrolysis, decomposition and synthesis during the deposition procedure. Therefore, with the increment of the Ni/Co ratio, less energy was left over for the particle growth, which was consistent with the SEM results in Fig. 6 5b, $d$ and f. Furthermore, this lower energy availability could also be ascribed to the disappearance of the flake-like nanostructures.

From the SEM analyses in Fig. 6 5g-1, less $\mathrm{NiCo}_{2} \mathrm{O}_{4}$-related compositions were deposited on the same Ni substrate by the SPFS process, compared to in the SPPS route. This might be due to the much lower temperature of the flame compared to the plasma plume, since less energy could be employed to synthesize the corresponding metal oxides. Also, the apparent flake-like nanostructures were not 
detected in these SPFS-deposited films; instead, as shown in in Fig. $65 \mathrm{~g}$, i and k, sphere-like parts (as marked by red circles) were observed in the resultant films. These spherical parts seem not to be composed of fine solid particles, while the surface microreliefs demonstrate the high possibility of insitu surface precipitation and synthesis in the SPFS-deposited $\mathrm{NiCo}_{2} \mathrm{O}_{4}$ samples. This feature can be more clearly observed in Fig. 6 5j and 1. Moreover, as reported in previous studies [52, 53], surface precipitation promotes the formation of hollow particles or shell structures. This agrees with our SEM results, since the hollow spheres with openings are more obviously detected in Fig. $65 \mathrm{i}$ and k. By contrast, some solid spherical particles were observed (as shown in Fig. 6 5g marked by yellow rectangles), indicating less surface precipitation in the F14 sample. This might have been due to the different solution concentrations in the raw precursors. In the F14 sample, since it had the lowest total concentration of $\mathrm{Co}$ and $\mathrm{Ni}$ salts, more time was required to achieve supersaturation and to form the consequent precipitation. Based on the previous study [52], rapid evaporation achieving supersaturation should be an important condition for "surface precipitation" in the solution precursor thermal spray. Therefore, more hollow spherical particles with openings were observed in the F11 and F12 samples.

$$
\begin{gathered}
\mathrm{Co}\left(\mathrm{NO}_{3}\right)_{2}+\mathrm{Ni}\left(\mathrm{NO}_{3}\right)_{2} \rightarrow \mathrm{NiCo}_{2} \mathrm{O}_{4} \quad(i) \\
\mathrm{Ni}\left(\mathrm{NO}_{3}\right)_{2} \rightarrow \mathrm{NiO} \quad \text { (ii) } \\
\mathrm{Co}\left(\mathrm{NO}_{3}\right)_{2} \rightarrow \mathrm{Co}_{3} \mathrm{O}_{4} \quad \text { (iii) }
\end{gathered}
$$

\subsection{Scratch test}

Three scratches were made on each sample. The penetration depth was measured at the load at $15 \mathrm{~N}$. The characteristic scratch channels for different samples were illustrated in Fig. S1, where the failure positions were marked by red dash lines. The results of the scratch test for different $\mathrm{NiCo}_{2} \mathrm{O}_{4}$ films on Ni substrates are summarized in Table 2. In general, the critical forces for all the samples are close to $9 \mathrm{~N}$, which is similar to the results from hydroxyapatite coatings deposited by suspension plasma spray method [30]. In addition, the SPPS-deposited films exhibited a little higher critical force than 
those of SPFS-deposited samples. It could be attributed to the higher temperature of plasma plume with better melting of feedstock, resulting in better bonding conditions between substrate and films.

\subsection{4 Electrochemical properties}

The electrochemical performances of SPPS-deposited and SPFS-deposited $\mathrm{NiCo}_{2} \mathrm{O}_{4}$ films as electrode materials were investigated in a three electrode electrolytic tank filled with $2 \mathrm{M} \mathrm{KOH}$ solution. Fig. 76 (a) shows the cyclic voltammetry (CV) curves of $\mathrm{NiCo}_{2} \mathrm{O}_{4}$ prepared by SPPS and SPFS routes from different $\mathrm{Ni} / \mathrm{Co}$ ratios in precursor solutions under $5 \mathrm{mV} / \mathrm{s}$ scan rate. It can be seen clearly the $\mathrm{NiCo}_{2} \mathrm{O}_{4}$ electrodes prepared by SPFS has quite higher specific capacity than that of SPPS process, which attribute to the hollow structure. The reversible redox peaks can be distinguished obviously in the CV curve of SPFS samples, as well as SPPS samples, implying the faradic behavior and a typical character of redox reaction of the SPFS-deposited $\mathrm{NiCo}_{2} \mathrm{O}_{4}$ films as active electrodes. The obvious pairs of oxidation-reduction peaks in the $\mathrm{NiCo}_{2} \mathrm{O}_{4}$ electrodes are concerned with the reversible reactions of $\mathrm{Co}^{2+} / \mathrm{Co}^{3+}$ and $\mathrm{Ni}^{2+} / \mathrm{Ni}^{3+}$ transitions in the following reaction (iv) and (v) $[18,20,54-56]$ ( $\mathrm{M}$ is on behalf of $\mathrm{Co}$ or $\mathrm{Ni}$ ):

$$
\begin{gathered}
\mathrm{NiCo}_{2} \mathrm{O}_{4}+\mathrm{OH}^{-}+\mathrm{H}_{2} \mathrm{O} \leftrightarrow \mathrm{NiOOH}+2 \mathrm{CoOOH}+\mathrm{e}^{-} \text {(iv) } \\
\mathrm{MOOH}+\mathrm{OH}^{-} \leftrightarrow \mathrm{MO}_{2}+\mathrm{H}_{2} \mathrm{O}+\mathrm{e}^{-}(v)
\end{gathered}
$$

As aforementioned in section 3.2, with the increment of $\mathrm{Ni} / \mathrm{Co}$ ratio, there is no redundant energy for the growth of particles in SPFS process, thus the electrode has more microstructure, which suggests higher specific area. A remarkable capacity of electrode can be obtained with the Ni/Co ratio of 1:2 or 1:1. As shown in Fig. 7 6a, sharp redox peak appears in the CV curve of F11 sample, which will strength the capacitive high-power output behavior. In addition, the areas under CV curves from SPFS-deposited are much larger than that of SPPS-deposited films, indicating much better specific capacitances were obtained from SPFS-prepared samples. The calculated specific capacitances from the six samples were illustrated as shown in Fig. 7 6b. The increment of specific capacitance of SPFSdeposited films compared to the SPPS-prepared samples was up to 20 times, attributing to the hollow 
microspheres and oxygen vacancies. The enhance performance from SPFS-deposited films could be ascribed to the surface morphologies, phase compositions and oxygen vacancies. Firstly, from SEM results in Fig.6g-1, it is clear that porous surface morphologies with hollow microspheres were obtained, especially for F11and F12 samples. As aforementioned in previous publications, the hollow architectures would improve ion diffusion with shortened pathway, as a result of enhanced capacitance $[12,13]$. Secondly, considering ultrahigh temperature of plasma plume, Ni substrates were easily to be oxidized during the SPPS deposition technology, resulting in more formation of NiO. This point is agreement with the results of GIXRD test. As such, more seriously oxidized Ni substrate would exhibit lower electrical conductivity, which would be harmful for capacitor performance. Moreover, in terms of XPS spectra and analyses (as illustrated in Fig.4 and Table S1), it was found that more oxygen vacancies were detected in SPFS-deposited films (F12 sample) than SPPS-deposited films (P12 sample). It was widely accepted that oxygen vacancies would be favorable for supercapacitors, attributed to the better diffusion for charge carriers and adsorption of $\mathrm{OH}$ - and more active sites $[16,17]$. In summary, the SPFS-deposited $\mathrm{NiCo}_{2} \mathrm{O}_{4}$ samples with more porous surface morphologies, more oxygen vacancies and less oxidation of $\mathrm{Ni}$ substrate promote higher specific capacitances. On the other hand, among all the SPFS-deposited films, better performance were observed from F11 and F12 samples compared to F14 sample, which should be due to more existences of hollow microspheres in both F11 and F12 samples (as shown in Fig.5i-1).

In addition, electrochemical impedance spectroscopy (EIS) was employed to detect the properties of charging and ion transfer in all the SPPS- and SPFS- deposited $\mathrm{NiCo}_{2} \mathrm{O}_{4}$ electrode films. The Nyquist plots is shown in Fig. 87 , and the inset gives an equivalent circuit in which Cdl is double layer capacitance, Rs is solution resistance, Rct is the Faradic charge transfer resistance, Rw is diffusive resistance and $\mathrm{Cw}$ is diffusive capacity. It can be seen the six electrodes have the similar, negligible solution resistance Rs, which demonstrates the electrochemical performance merely depended on the electrode contents and structures. In the high frequency region, the electrodes obtained via SPPS exhibited higher charge transfer resistance than SPFS electrodes, thus the electronic conductivity of the SPFS electrodes is quite better than the SPPS electrodes. In the low frequency region, all of them 
have a shape of near line, and the slope of the line represents the diffusive behaviors of the electrolyte in electrode pores and ions in active materials. It is clear that the SPPS samples have a smaller slope, implying they have higher diffusive resistance than the SPFS samples. The diffusive resistance dominated by a variety of microstructure is corresponding to the SEM morphologies analysis: the hollow sphere-like particles revealed in SPFS samples provide shorter diffusion path. The nearvertical line in the low frequency region of SPFS samples indicates fast diffusion occurring in the interface and electrode, indicating a key feature of an ideal capacitive behavior. Based on the discussion in the XPS analysis, more oxygen vacancies were observed in the SPFS sample. As reported in previous studies, oxygen vacancies will improve conductivity and enhance diffusion of charge carriers [17, 51], which should be be attributing to the near-vertical line in the low frequency region of SPFS samples.

Based on the discussion and analyses above, the samples prepared via SPFS can be quite better candidates for electrodes in supercapacitors. The F11 film electrode is further evaluated by CV measurement under various scan rates and GDC measurement at different current densities, as illustrated in Fig. 8a and b. It can be seen clearly that the CV curve can still keep distinct redox peak and symmetrical shape even under the high scan rate of $200 \mathrm{mV} / \mathrm{s}$, indicating the excellent electrochemical activity and quick response of reversible reaction on the electrode. Besides, the F14 and F12 samples were also evaluated by CV tests under different scan rates as shown in Fig. S1 S2 and Fig. S2 S3. The symmetrical CV curves with two obvious reduction and oxidation peaks were also observed under the scan rate up to $200 \mathrm{mV} / \mathrm{s}$, benefiting from hollow microspheres and oxygen vacancies as well. By contrast, the CV curves of P12 sample under different scan rates as illustrated in Fig. S3 S4 were more asymmetric, indicating a more serious irreversible redox procedure occurred in the SPPS-prepared $\mathrm{NiCo}_{2} \mathrm{O}_{4}$ rather than in SPFS-deposited $\mathrm{NiCo}_{2} \mathrm{O}_{4}$ electrodes. This irreversible procedure is from the insufficient redox reactions, which should be inefficient transportation of ions and electrons due to less of hollow micro-/nanostructured architectures and oxygen vacancies. 
Fig. 8b shows the charge-discharge behaviors of the F11 electrode at different current densities from $1 \mathrm{~A} / \mathrm{g}$ to $20 \mathrm{~A} / \mathrm{g}$. Due to the redox reaction in the electrode, charge-discharge platforms at small current density suggest better pseudocapacitive behavior of the electrodes, resulting higher specific capacitances. The specific capacitances are plotted as a function of scan rates and current densities in Fig. $8 \mathrm{c}(\mathrm{e})$, which decreased gradually with increment of scan rates and current densities. When the scan rate increased from $5 \mathrm{mV} / \mathrm{s}$ to $50 \mathrm{mV} / \mathrm{s}$ in the $\mathrm{CV}$ measurement, the specific capacitance still remains $186 \mathrm{~F} / \mathrm{g}$ from $351 \mathrm{~F} / \mathrm{g}$ at $5 \mathrm{mV} / \mathrm{s}$, indicating rate capability as high as $53 \%$ retention. And with the increment of current density from $1 \mathrm{~A} / \mathrm{g}$ to $20 \mathrm{~A} / \mathrm{g}$, the specific capacitance keeps $504 \mathrm{~F} / \mathrm{g}$, suggesting a high rate capability as well (56\% rentention). This could be attributed to the fast kinetics of redox of the electrode material should be not only related to the hollow microspheres or shell structures (as shown in Fig. 6k-l), but also the in-situ oxygen vacancies with better absorbing of $\mathrm{OH}^{-}$ will also promote the redox reaction between $\mathrm{NiCO}_{2} \mathrm{O}_{4}$ and $\mathrm{KOH}$ solution [13]. The specific capacitances of $\mathrm{NiCo}_{2} \mathrm{O}_{4}$ based on electrodes from other preparation technologies were listed in Table 3. The enhanced specific capacitance from the SPFS-deposited $\mathrm{NiCo}_{2} \mathrm{O}_{4}$ films (F11 sample) were obtained, which could be attributed to synergic effect of hollow microspheres and oxygen vacancies. Besides, the binder-free feature was believed as another contributor for the enhanced performance, since better transportation of electrons and the diffusion of ions would be expected. Apart from the synergistic effect of oxygen vacancy and microspheres, the binder free feature is also help for transportation of electrons and diffusion of ions. As summarized in Table 2 , the SPFS-deposited films (F11 samples) exhibited better or comparable specific capacitance compared to the previous studies.

Moreover, cycling performance is another important factor for the practical promotion. Fig.8d (d) shows a 2500 cycles CV test of F11 electrode at $20 \mathrm{mV} / \mathrm{s}$ scan rate. An almost horizontal line is displayed, suggesting an excellent cycle stability of $\mathrm{F} 11 \mathrm{NiCo}_{2} \mathrm{O}_{4}$ electrode. After 2500 cycles, the electrode shows specific capacitance retention of $89.2 \%$. The result reveals that the electrode material has an extremely stable structure and good capacitive behavior. And the good retention performance could be an indirect sign for the enough strength for these SPTS-deposited films under electrochemical investigations. 


\section{Conclusions}

The oxygen-vacancies $\mathrm{NiCo}_{2} \mathrm{O}_{4}$ films with hollow microspheres deposited on $\mathrm{Ni}$ substrate as good candidates of supercapacitor electrodes were originally realized via such rapid one-step solution precursor thermal spray technology. The GIXRD XRD, Raman and XPS results confirmed the formation of $\mathrm{NiCo}_{2} \mathrm{O}_{4}$ phases in all the samples. The surface morphologies of as-deposited porous $\mathrm{NiCO}_{2} \mathrm{O}_{4}$ films were more sensitive to the heat source rather than the $\mathrm{Ni} / \mathrm{Co}$ ratio in the raw precursor solutions. Particularly, the SPFS-deposited $\mathrm{NiCO}_{2} \mathrm{O}_{4}$ films exhibited hollow microspheres instead of the solid particles prepared via SPPS route. The scratch test revealed the critical load is around $9 \mathrm{~N}$. The higher specific area and lower diffusion resistance resulted from the hollow microspheres and enhanced oxygen-vacancies in the SPFS samples processes better pseudocapacitive behavior than the SPPS-deposited films. In particular, in light of CV test, the specific capacitances as $373 \mathrm{~F} / \mathrm{g}$ from SPFS-deposited films, exhibiting about 20 times increment compared to the SPPS-deposited films. The specific capacitance of SPFS-deposited $\mathrm{NiCo}_{2} \mathrm{O}_{4}$ electrodes is as high as $902 \mathrm{~F} / \mathrm{g}$ at $1 \mathrm{~A} / \mathrm{g}$ current density. The rate capability under high current density of $20 \mathrm{~A} / \mathrm{g}$ is up to $56 \%$ and cycling performance after 2500 cycles still kept $89.2 \%$ retention. This work not only obtained betterperformance $\mathrm{NiCo}_{2} \mathrm{O}_{4}$ electrodes with oxygen-deficient hollow microspheres films by such a novel rapid one-step technology, but also proposed an interesting approach for synthesizing and depositing other metal oxide films for supercapacitor applications.

\section{Acknowledgments}

One of the authors Yangzhou MA acknowledges the grants from Anhui Provincial Natural Science Research Project (KJ2017A059). The authors, Zexin YU and Meimei LIU, gratefully appreciate to the support from the China Scholarship Council (Grant No. 201504490038 and Grant No. 201604490072). The author, Chen SONG, would like appreciate to the financial support from Science and Technology Planning Project of Guangdong Province (No. 2017A070701027). 


\section{References}

[1] C. Yuan, H.B. Wu, Y. Xie, X.W. Lou, Mixed transition - metal oxides: design, synthesis, and energy - related applications, Angew. Chem. Int. Ed., 53 (2014) 1488-1504.

[2] A. González, E. Goikolea, J.A. Barrena, R. Mysyk, Review on supercapacitors: Technologies and materials, Renewable and Sustainable Energy Reviews, 58 (2016) 1189-1206.

[3] M. Vangari, T. Pryor, L. Jiang, Supercapacitors: review of materials and fabrication methods, Journal of Energy Engineering, 139 (2012) 72-79.

[4] X. Chen, Y. Huang, X. Han, K. Zhang, Synthesis of cobalt nanofibers@ nickel sulfide nanosheets hierarchical core-shell composites for anode materials of lithium ion batteries, Electrochim. Acta, 284 (2018) 418-426.

[5] G. Wang, L. Zhang, J. Zhang, A review of electrode materials for electrochemical supercapacitors, Chem. Soc. Rev., 41 (2012) 797-828.

[6] P. Simon, Y. Gogotsi, Materials for electrochemical capacitors, Nanoscience And Technology: A Collection of Reviews from Nature Journals, World Scientific2010, pp. 320-329.

[7] L.L. Zhang, X. Zhao, Carbon-based materials as supercapacitor electrodes, Chem. Soc. Rev., 38 (2009) 2520-2531.

[8] K.H. An, W.S. Kim, Y.S. Park, Y.C. Choi, S.M. Lee, D.C. Chung, D.J. Bae, S.C. Lim, Y.H. Lee, Supercapacitors using single - walled carbon nanotube electrodes, Adv. Mater., 13 (2001) 497-500.

[9] M. Winter, R.J. Brodd, What are batteries, fuel cells, and supercapacitors?, ACS Publications, 2004.

[10] D.P. Dubal, P. Gomez-Romero, B.R. Sankapal, R. Holze, Nickel cobaltite as an emerging material for supercapacitors: An overview, Nano Energy, 11 (2015) 377-399. 
[11] S.-K. Chang, Z. Zainal, K.-B. Tan, N.A. Yusof, W.M.D. Wan Yusoff, S.R.S. Prabaharan, Recent development in spinel cobaltites for supercapacitor application, Ceram. Int., 41 (2015) 114.

[12] X. Qi, W. Zheng, G. He, T. Tian, N. Du, L. Wang, $\mathrm{NiCo}_{2} \mathrm{O}_{4}$ hollow microspheres with tunable numbers and thickness of shell for supercapacitors, Chem. Eng. J., 309 (2017) 426-434.

[13] L. Wang, X. Jiao, P. Liu, Y. Ouyang, X. Xia, W. Lei, Q. Hao, Self-template synthesis of yolk-shelled NiCo2O4 spheres for enhanced hybrid supercapacitors, Appl. Surf. Sci., 427 (2018) 174-181.

[14] C. Zhu, S. Fu, D. Du, Y. Lin, Facilely Tuning Porous $\mathrm{NiCo}_{2} \mathrm{O}_{4}$ Nanosheets with Metal Valence - State Alteration and Abundant Oxygen Vacancies as Robust Electrocatalysts Towards Water Splitting, Chemistry-A European Journal, 22 (2016) 4000-4007.

[15] Z. Yu, H. Moussa, M. Liu, B. Chouchene, R. Schneider, W. Wang, M. Moliere, H. Liao, Tunable morphologies of $\mathrm{ZnO}$ films via the solution precursor plasma spray process for improved photocatalytic degradation performance, Appl. Surf. Sci., 455 (2018) 970-979.

[16] T. Zhai, S. Xie, M. Yu, P. Fang, C. Liang, X. Lu, Y. Tong, Oxygen vacancies enhancing capacitive properties of $\mathrm{MnO} 2$ nanorods for wearable asymmetric supercapacitors, Nano Energy, 8 (2014) 255-263.

[17] K. Chi, Z. Zhang, Q. Lv, C. Xie, J. Xiao, F. Xiao, S. Wang, Well-ordered oxygen-deficient CoMoO4 and $\mathrm{Fe} 2 \mathrm{O} 3$ nanoplate arrays on 3D graphene foam: toward flexible asymmetric supercapacitors with enhanced capacitive properties, ACS applied materials \& interfaces, 9 (2017) 6044-6053.

[18] J. Pu, J. Wang, X. Jin, F. Cui, E. Sheng, Z. Wang, Porous hexagonal NiCo2O4 nanoplates as electrode materials for supercapacitors, Electrochim. Acta, 106 (2013) 226-234. 
[19] C. Yuan, J. Li, L. Hou, J. Lin, X. Zhang, S. Xiong, Polymer-assisted synthesis of a 3D hierarchical porous network-like spinel $\mathrm{NiCo}_{2} \mathrm{O}_{4}$ framework towards high-performance electrochemical capacitors, Journal of Materials Chemistry A, 1 (2013) 11145-11151.

[20] Y.Q. Wu, X.Y. Chen, P.T. Ji, Q.Q. Zhou, Sol-gel approach for controllable synthesis and electrochemical properties of $\mathrm{NiCo} 2 \mathrm{O} 4$ crystals as electrode materials for application in supercapacitors, Electrochim. Acta, 56 (2011) 7517-7522.

[21] Y. Zheng, Z. Li, J. Xu, T. Wang, X. Liu, X. Duan, Y. Ma, Y. Zhou, C. Pei, Multi-channeled hierarchical porous carbon incorporated $\mathrm{Co}_{3} \mathrm{O}_{4}$ nanopillar arrays as 3D binder-free electrode for high performance supercapacitors, Nano Energy, 20 (2016) 94-107.

[22] X.-C. Dong, H. Xu, X.-W. Wang, Y.-X. Huang, M.B. Chan-Park, H. Zhang, L.-H. Wang, W. Huang, P. Chen, 3D graphene-cobalt oxide electrode for high-performance supercapacitor and enzymeless glucose detection, ACS nano, 6 (2012) 3206-3213.

[23] H.-K. Kim, T.-Y. Seong, J.-H. Lim, W.I. Cho, Y.S. Yoon, Electrochemical and structural properties of radio frequency sputtered cobalt oxide electrodes for thin-film supercapacitors, J. Power Sources, 102 (2001) 167-171.

[24] P.L. Fauchais, J.V. Heberlein, M.I. Boulos, Thermal Spray Fundamentals: From Powder to Part, Springer, New York, 2014.

[25] M. Gell, E.H. Jordan, M. Teicholz, B.M. Cetegen, N.P. Padture, L. Xie, D. Chen, X. Ma, J. Roth, Thermal barrier coatings made by the solution precursor plasma spray process, J. Therm. Spray Technol., 17 (2008) 124-135.

[26] H. Hawthorne, B. Arsenault, J. Immarigeon, J. Legoux, V. Parameswaran, Comparison of slurry and dry erosion behaviour of some HVOF thermal sprayed coatings, Wear, 225 (1999) 825-834.

[27] G.-J. Yang, C.-J. Li, S.-J. Zhang, C.-X. Li, High-temperature erosion of HVOF sprayed Cr 3 C 2-NiCr coating and mild steel for boiler tubes, J. Therm. Spray Technol., 17 (2008) 782-787. 
[28] Z. Yu, H. Moussa, Y. Ma, M. Liu, B. Chouchene, R. Schneider, M. Moliere, H. Liao, Oxygen-defective $\mathrm{ZnO}$ films with various nanostructures prepared via a rapid one-step process and corresponding photocatalytic degradation applications, J. Colloid Interface Sci., 534 (2019) 637-648.

[29] S. Kozerski, L. Łatka, L. Pawlowski, F. Cernuschi, F. Petit, C. Pierlot, H. Podlesak, J.P. Laval, Preliminary study on suspension plasma sprayed $\mathrm{ZrO} 2+8$ wt.\% Y2O3 coatings, J. Eur. Ceram. Soc., 31 (2011) 2089-2098.

[30] L. Łatka, L. Pawlowski, D. Chicot, C. Pierlot, F. Petit, Mechanical properties of suspension plasma sprayed hydroxyapatite coatings submitted to simulated body fluid, Surf. Coat. Technol., 205 (2010) 954-960.

[31] Y. Zhu, Z. Wu, M. Jing, W. Song, H. Hou, X. Yang, Q. Chen, X. Ji, 3D network-like mesoporous NiCo $2 \mathrm{O} 4$ nanostructures as advanced electrode material for supercapacitors, Electrochimica Acta, 149 (2014) 144-151.

[32] F. Yang, J. Yao, F. Liu, H. He, M. Zhou, P. Xiao, Y. Zhang, Ni-Co oxides nanowire arrays grown on ordered $\mathrm{TiO}_{2}$ nanotubes with high performance in supercapacitors, Journal of Materials Chemistry A, 1 (2013) 594-601.

[33] J. Yan, T. Wei, W. Qiao, B. Shao, Q. Zhao, L. Zhang, Z. Fan, Rapid microwave-assisted synthesis of graphene nanosheet/Co3O4 composite for supercapacitors, Electrochim. Acta, 55 (2010) 6973-6978.

[34] Y. Wang, S. Huang, Y. Lu, S. Cui, W. Chen, L. Mi, High-rate-capability asymmetric supercapacitor device based on lily-like $\mathrm{Co}_{3} \mathrm{O}_{4}$ nanostructures assembled using nanowires, RSC Advances, 7 (2017) 3752-3759.

[35] Q. Hu, Z. Gu, X. Zheng, X. Zhang, Three-dimensional Co3O4@ NiO hierarchical nanowire arrays for solid-state symmetric supercapacitor with enhanced electrochemical performances, Chem. Eng. J., 304 (2016) 223-231. 
[36] G.-S. Jang, S. Ameen, M.S. Akhtar, H.-S. Shin, Cobalt oxide nanocubes as electrode material for the performance evaluation of electrochemical supercapacitor, Ceram. Int., 44 (2018) 588-595.

[37] Q. Ke, C. Tang, Z.-C. Yang, M. Zheng, L. Mao, H. Liu, J. Wang, 3D nanostructure of carbon nanotubes decorated $\mathrm{Co}_{3} \mathrm{O}_{4}$ nanowire arrays for high performance supercapacitor electrode, Electrochim. Acta, 163 (2015) 9-15.

[38] Z.-Y. Li, P.T. Bui, D.-H. Kwak, M.S. Akhtar, O.-B. Yang, Enhanced electrochemical activity of low temperature solution process synthesized $\mathrm{Co}_{3} \mathrm{O}_{4}$ nanoparticles for pseudosupercapacitors applications, Ceram. Int., 42 (2016) 1879-1885.

[39] W. Zhang, Y. Su, X. Zhang, Y. Yang, X. Guo, Facile synthesis of porous NiCo 2 O 4 nanoflakes as magnetic recoverable catalysts towards the efficient degradation of $\mathrm{RhB}$, RSC Advances, 6 (2016) 64626-64633.

[40] Z.-Q. Liu, K. Xiao, Q.-Z. Xu, N. Li, Y.-Z. Su, H.-J. Wang, S. Chen, Fabrication of hierarchical flower-like super-structures consisting of porous NiCo2O4 nanosheets and their electrochemical and magnetic properties, Rsc Advances, 3 (2013) 4372-4380.

[41] S. Yue, H. Tong, L. Lu, W. Tang, W. Bai, F. Jin, Q. Han, J. He, J. Liu, X. Zhang, Hierarchical NiCo2O4 nanosheets/nitrogen doped graphene/carbon nanotube film with ultrahigh capacitance and long cycle stability as a flexible binder-free electrode for supercapacitors, Journal of Materials Chemistry A, 5 (2017) 689-698.

[42] Y. Zhang, Y. Zhang, D. Zhang, L. Sun, Urchin-like NiCo2O4 nanoneedles grown on mesocarbon microbeads with synergistic electrochemical properties as electrodes for symmetric supercapacitors, Dalton Transactions, 46 (2017) 9457-9465.

[43] M. Rashad, M. Rüsing, G. Berth, K. Lischka, A. Pawlis, CuO and Co3O4 nanoparticles: synthesis, characterizations, and Raman spectroscopy, Journal of Nanomaterials, 2013 (2013) 82.

[44] E.M. Mwenesongole, A Raman-and XRD study of the crystal chemistry of cobalt blue, University of Pretoria, 2008. 
[45] G.A. Babu, G. Ravi, Y. Hayakawa, Microwave synthesis and effect of CTAB on ferromagnetic properties of $\mathrm{NiO}, \mathrm{Co} 3 \mathrm{O} 4$ and NiCo2O4 nanostructures, Appl. Phys. A, 119 (2015) 219-232.

[46] X. Li, A. Dhanabalan, C. Wang, Enhanced electrochemical performance of porous NiO-Ni nanocomposite anode for lithium ion batteries, J. Power Sources, 196 (2011) 9625-9630.

[47] W. Wang, Y. Liu, C. Xu, C. Zheng, G. Wang, Synthesis of NiO nanorods by a novel simple precursor thermal decomposition approach, Chem. Phys. Lett., 362 (2002) 119-122.

[48] R. Dietz, G. Parisot, A. Meixner, Infrared absorption and Raman scattering by two-magnon processes in NiO, Physical Review B, 4 (1971) 2302.

[49] J. Zhao, Z. Li, M. Zhang, A. Meng, Q. Li, Direct growth of ultrathin NiCo2O4/NiO nanosheets on $\mathrm{SiC}$ nanowires as a free-standing advanced electrode for high-performance asymmetric supercapacitors, ACS Sustainable Chemistry \& Engineering, 4 (2016) 3598-3608.

[50] Y. Zhu, Y. Huang, M. Wang, K. Wang, M. Yu, X. Chen, Z. Zhang, Novel carbon coated core-shell heterostructure $\mathrm{NiCo} 2 \mathrm{O} 4 @ \mathrm{NiO}$ grown on carbon cloth as flexible lithium-ion battery anodes, Ceram. Int., (2018).

[51] D. Yan, W. Wang, X. Luo, C. Chen, Y. Zeng, Z. Zhu, NiCo2O4 with oxygen vacancies as better performance electrode material for supercapacitor, Chem. Eng. J., 334 (2018) 864-872.

[52] A. Saha, S. Seal, B. Cetegen, E. Jordan, A. Ozturk, S. Basu, Thermo-physical processes in cerium nitrate precursor droplets injected into high temperature plasma, Surf. Coat. Technol., 203 (2009) 2081-2091.

[53] P. Fauchais, A. Vardelle, Solution and suspension plasma spraying of nanostructure coatings, Advanced Plasma Spray Applications, InTech2012.

[54] J. Xiao, S. Yang, Sequential crystallization of sea urchin-like bimetallic (Ni, Co) carbonate hydroxide and its morphology conserved conversion to porous NiCo 2 O 4 spinel for pseudocapacitors, RSC Advances, 1 (2011) 588-595. 
[55] X. Lu, X. Huang, S. Xie, T. Zhai, C. Wang, P. Zhang, M. Yu, W. Li, C. Liang, Y. Tong, Controllable synthesis of porous nickel-cobalt oxide nanosheets for supercapacitors, J. Mater. Chem., 22 (2012) 13357-13364.

[56] R.R. Salunkhe, K. Jang, H. Yu, S. Yu, T. Ganesh, S.-H. Han, H. Ahn, Chemical synthesis and electrochemical analysis of nickel cobaltite nanostructures for supercapacitor applications, J. Alloys Compd., 509 (2011) 6677-6682.

[57] C. Ji, F. Liu, L. Xu, S. Yang, Urchin-like $\mathrm{NiCO}_{2} \mathrm{O}_{4}$ hollow microspheres and $\mathrm{FeSe}_{2}$ microsnowflakes for flexible solid-state asymmetric supercapacitors, Journal of Materials Chemistry A, 5 (2017) 5568-5576.

[58] C. Yuan, J. Li, L. Hou, J. Lin, G. Pang, L. Zhang, L. Lian, X. Zhang, Template-engaged synthesis of uniform mesoporous hollow NiCo 2 O 4 sub-microspheres towards highperformance electrochemical capacitors, Rsc Advances, 3 (2013) 18573-18578.

[59] M. Kuang, W. Zhang, X.L. Guo, L. Yu, Y.X. Zhang, Template-free and large-scale synthesis of hierarchical dandelion-like $\mathrm{NiCo} 2 \mathrm{O} 4$ microspheres for high-performance supercapacitors, Ceram. Int., 40 (2014) 10005-10011.

[60] L. Huang, W. Zhang, J. Xiang, Y. Huang, Porous $\mathrm{NiCo}_{2} \mathrm{O}_{4} / \mathrm{C}$ nanofibers replicated by cotton template as high-rate electrode materials for supercapacitors, Journal of Materiomics, 2 (2016) 248-255.

[61] N. Jabeen, Q. Xia, M. Yang, H. Xia, Unique core-shell nanorod arrays with polyaniline deposited into mesoporous NiCo2O4 support for high-performance supercapacitor electrodes, ACS applied materials \& interfaces, 8 (2016) 6093-6100.

[62] J. Xu, L. Li, P. Gao, L. Yu, Y. Chen, P. Yang, S. Gai, P. Yang, Facile preparation of $\mathrm{NiCo} 2 \mathrm{O} 4$ nanobelt/graphene composite for electrochemical capacitor application, Electrochim. Acta, 166 (2015) 206-214. 


\section{Figure captions:}

Fig.1 Schematic diagram of (a) Solution Precursor Plasma Spray (SPPS) and (b) Solution Precursor Flame spray (SPFS) processes.

Fig.2. Grazing-incidence XRD patterns of $\mathrm{NiCo}_{2} \mathrm{O}_{4}$ films deposited on $\mathrm{Ni}$ substrate with different precursor solutions by SPPS and SPFS routes.

Fig.2 XRD patterns of (a) P14, (b) P12 and (c) P11 samples.

Fig. 3 XRD patterns of (a) F14, (b) F12 and (c) F11 samples.

Fig.4 3 Raman spectra of (a) P14, (b) P12, (c) P11 and (d) F14, (e) F12 and (f) F11 samples.

Fig. 54 XPS spectra of the P12 sample: a) survey, b) Ni 2p spectra, c) Co 2p spectra and d) O 1s spectra and of the F12 sample: e) survey, f) Ni 2p spectra, g) Co 2p spectra and h) O 1s spectra respectively.

Fig. 65 Surface morphologies of (a, b) P14, (c, d) P12 and (e, f) P11 and (g, h) F14, (i, j) F12 and (k, l) F11 samples under low and high magnifications. (The yellow cycles marks the flake nanostructures and red cycle marks the sphere-like particles)

Fig. 76 The electrochemical performance of the electrodes prepared by SPFS and SPPS process with different Ni/Co ratios: (a) Cyclic voltammetry (CV) curves (the insert shows the details of the SPPS electrode CV performance) and (b) calculated specific capacitances.

Fig.8 7 Nyquist plots of the P14, P12, P11 and F14, F12 and F11 electrodes

Fig. 98 The electrochemical performance of F11 samples: (a) cyclic voltammetry with different scan rates, (b) galvanostatic discharge-charge with different current densities, (c) specific capacitance decay as a function of different scan rates and current densities, (d) cycle performance of the electrodes during 2500 cycles at the scan rate of $20 \mathrm{mV} / \mathrm{s}$

\section{Table captions}


Table 1 Spraying parameters for the $\mathrm{NiCo}_{2} \mathrm{O}_{4}$ films from different solution ratios via SPPS and SPFS processes

Table 2. Results of the scratch test for six different $\mathrm{NiCo}_{2} \mathrm{O}_{4}$ films

Table $z 3$ Summary of specific capacitances from $\mathrm{NiCo}_{2} \mathrm{O}_{4}$ related electrodes 


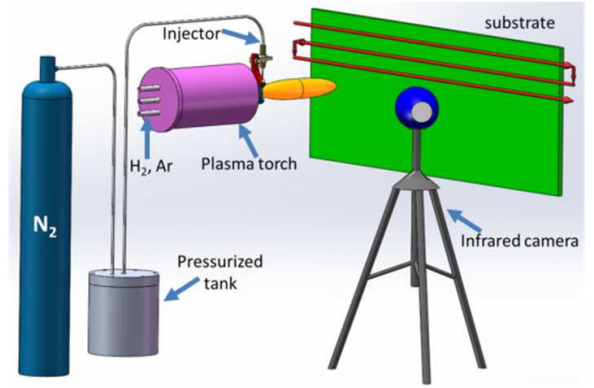

(a)

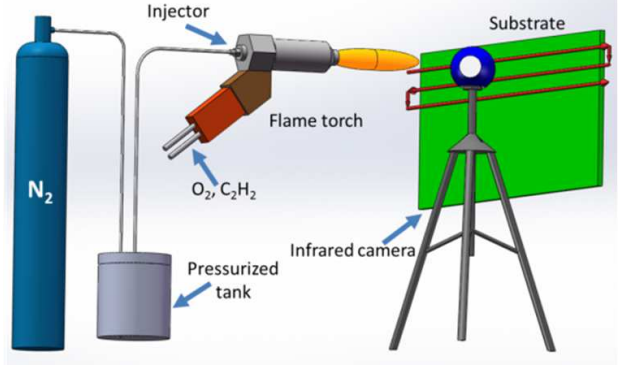

(b)

Fig.1 Schematic diagram of (a) Solution Precursor Plasma Spray (SPPS) and (b) Solution Precursor Flame spray (SPFS) processes.
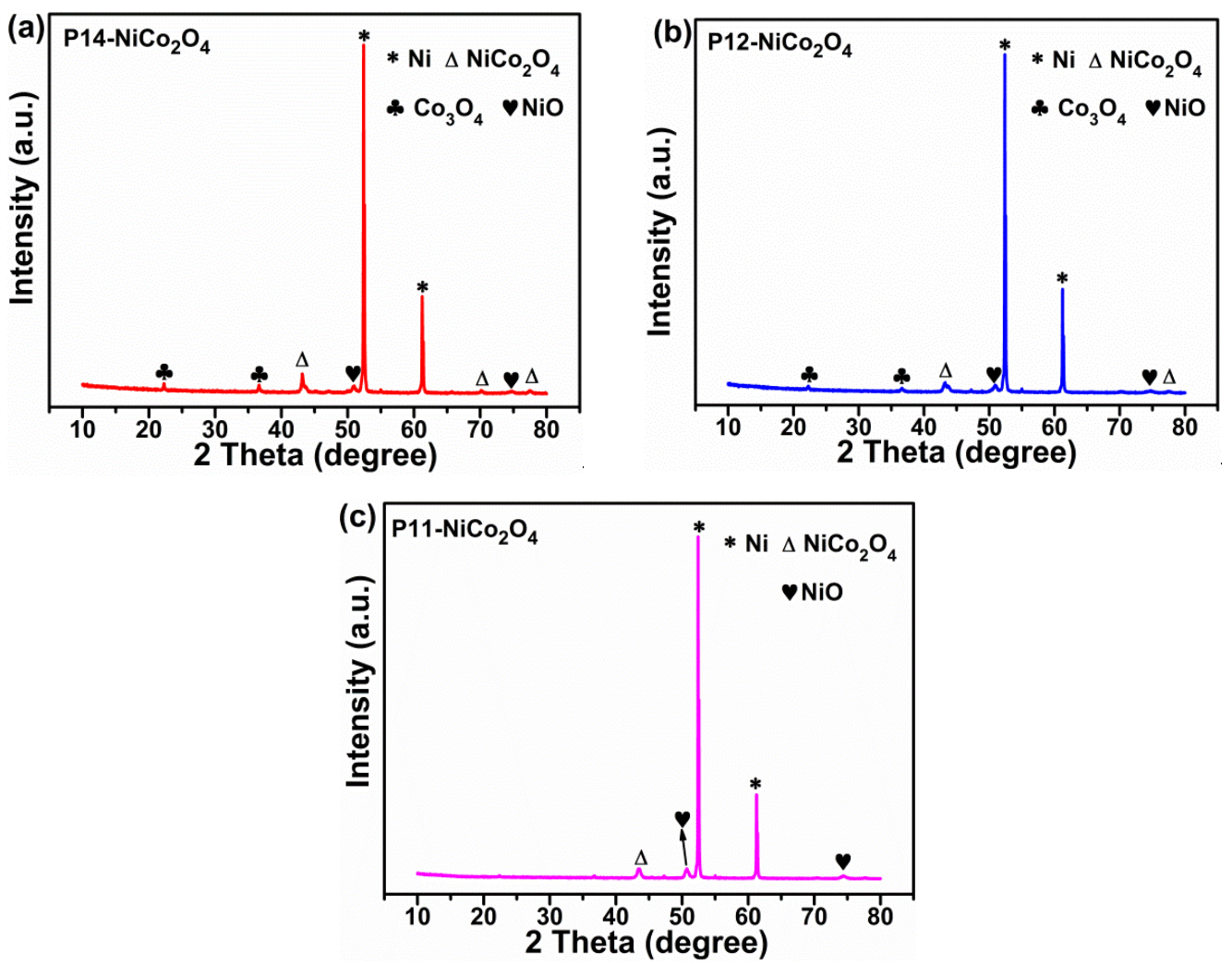

Fig. 2 XRD patterns of (a) P14, (b) P12 and (c) P11 samples. 

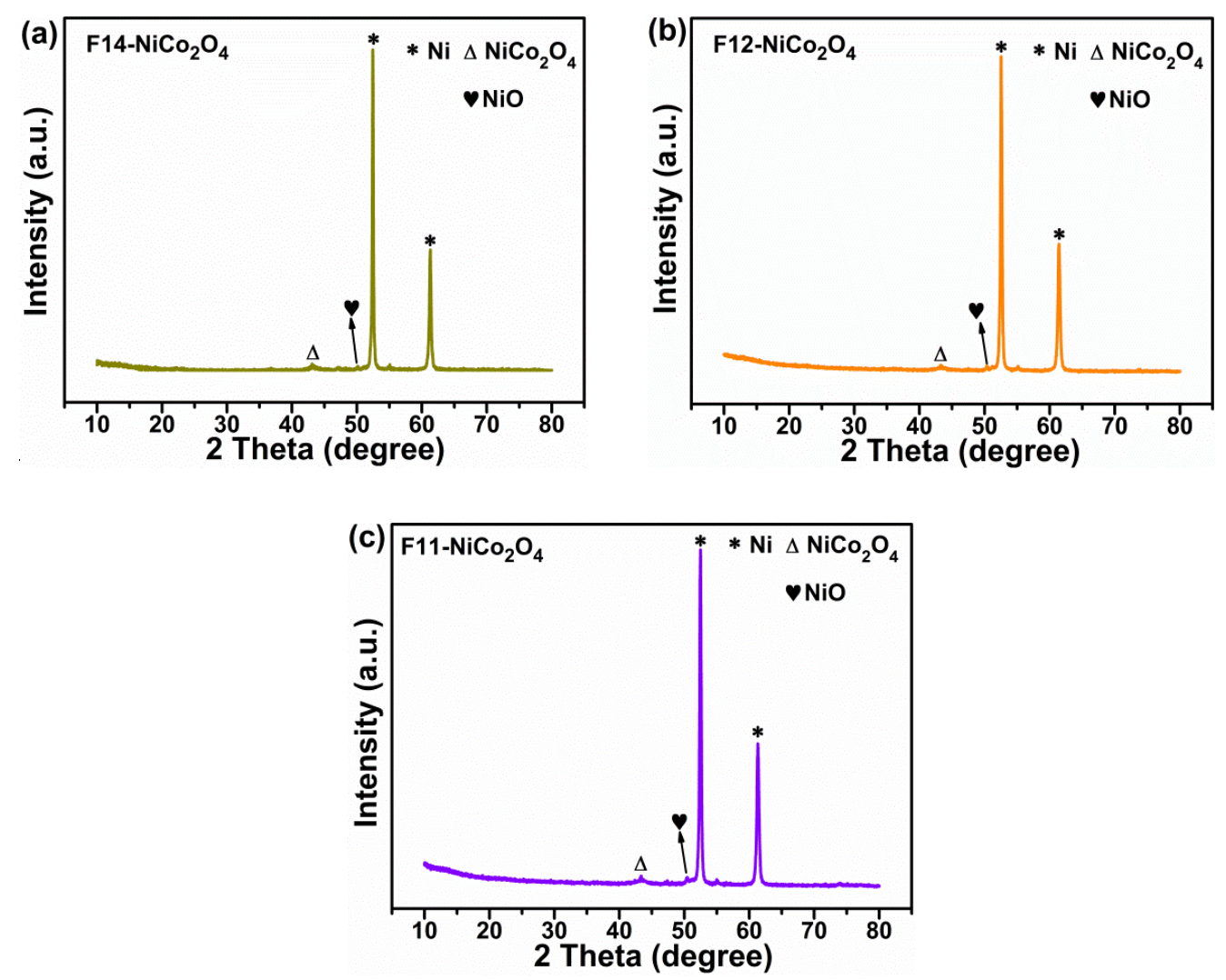

Fig. 3 XRD patterns of (a) F14, (b) F12 and (c) F11-samples. 

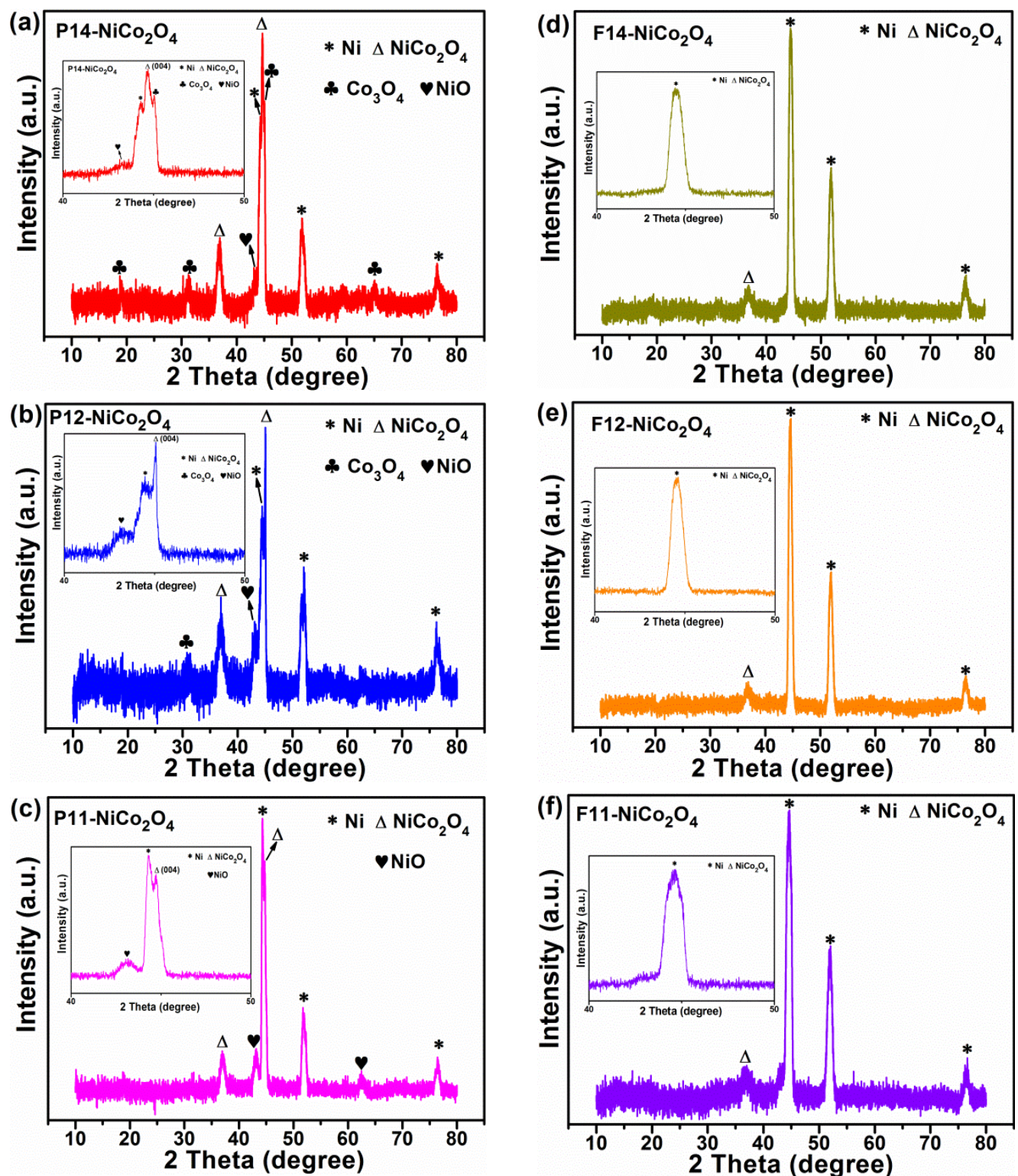

Fig. 2. Grazing-incidence XRD patterns of $\mathrm{NiCO}_{2} \mathrm{O}_{4}$ films deposited on $\mathrm{Ni}$ substrate with different precursor solutions by SPPS and SPFS routes. 

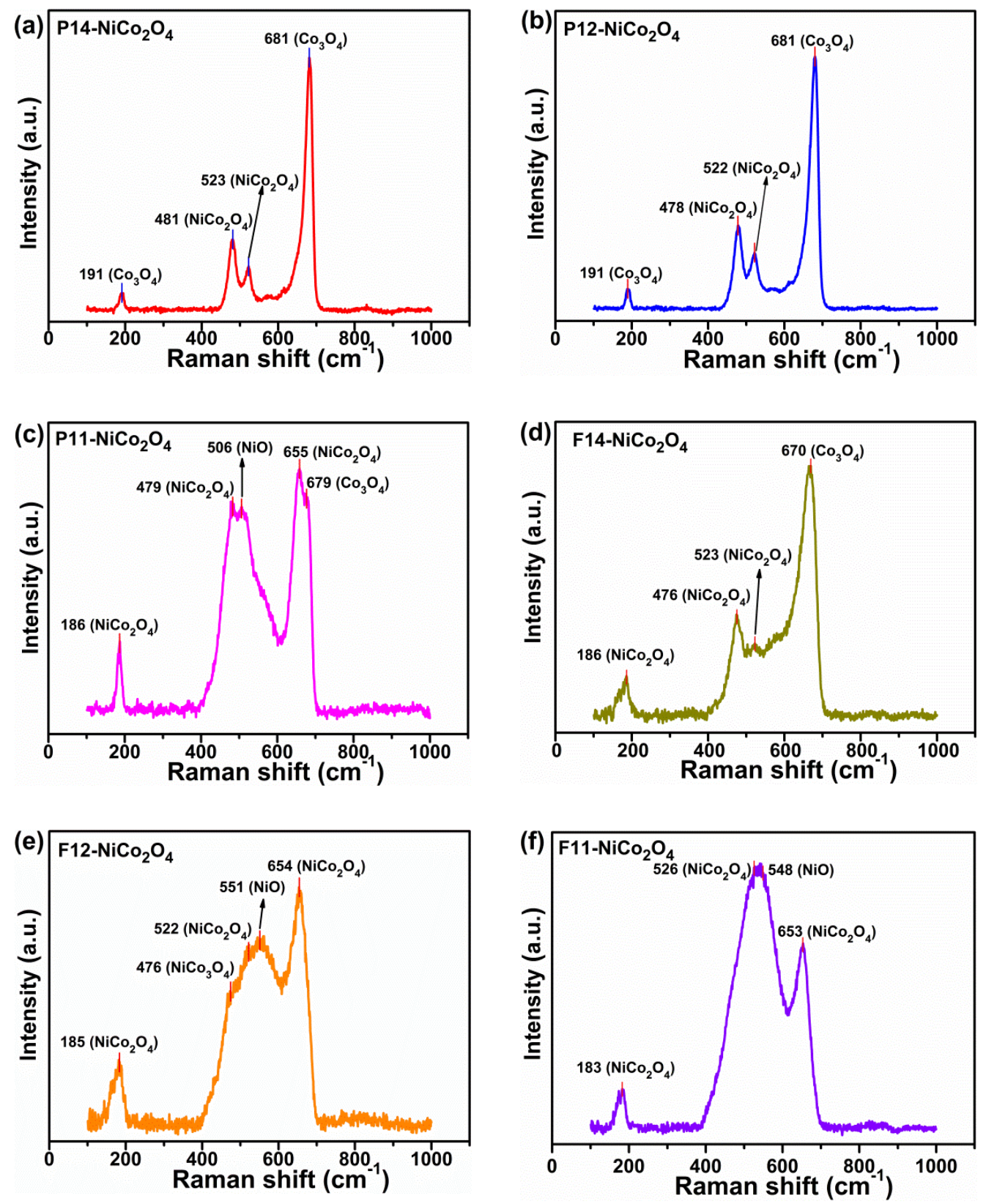

Fig. 43 Raman spectra of (a) P14, (b) P12, (c) P11 and (d) F14, (e) F12 and (f) F11 samples. 

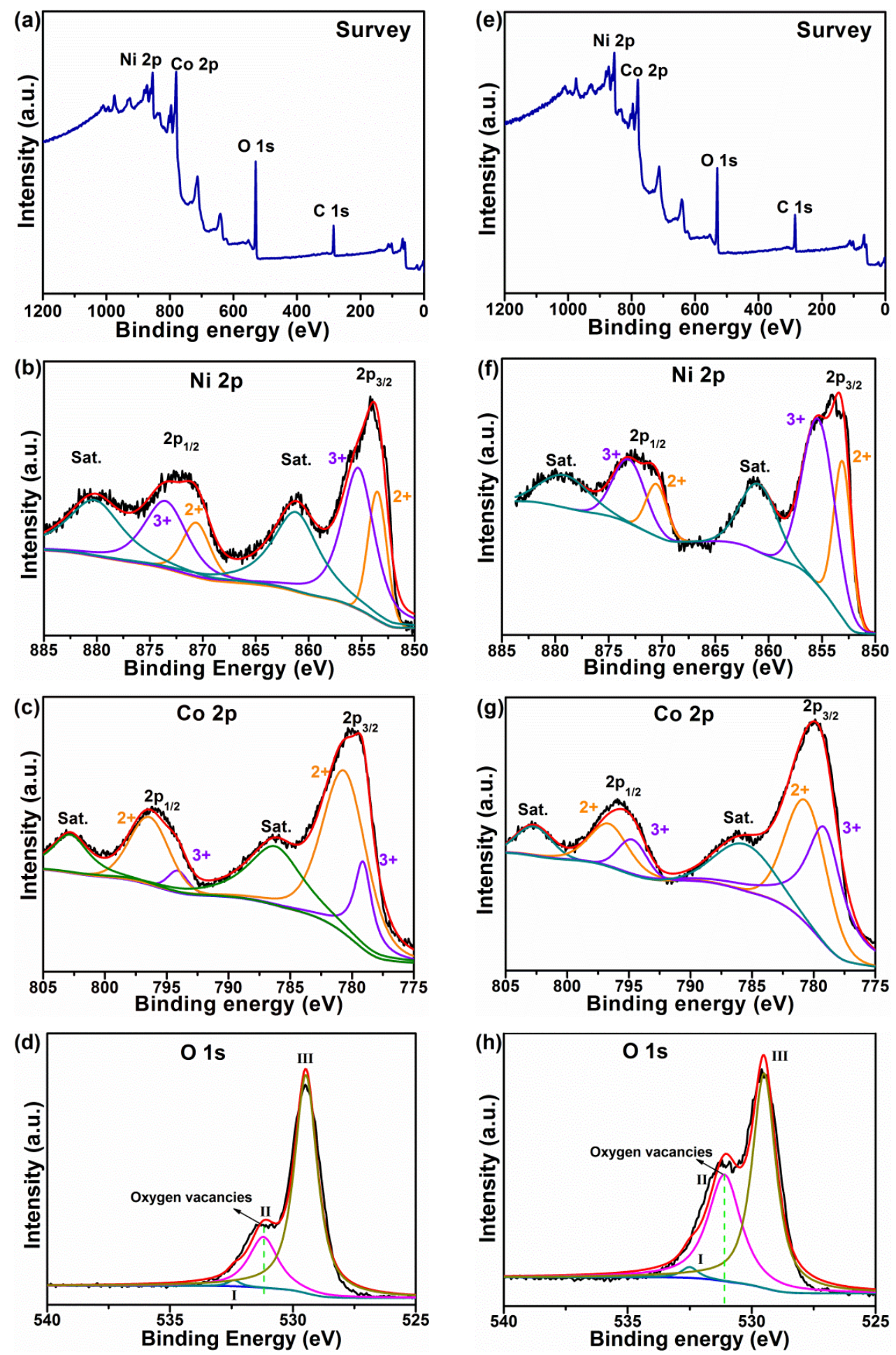

Fig. 54 XPS spectra of the P12 sample: a) survey, b) Ni 2p spectra, c) Co 2p spectra and d) O 1s spectra and of the F12 sample: e) survey, f) Ni 2p spectra, g) Co 2p spectra and h) O 1s spectra respectively. 

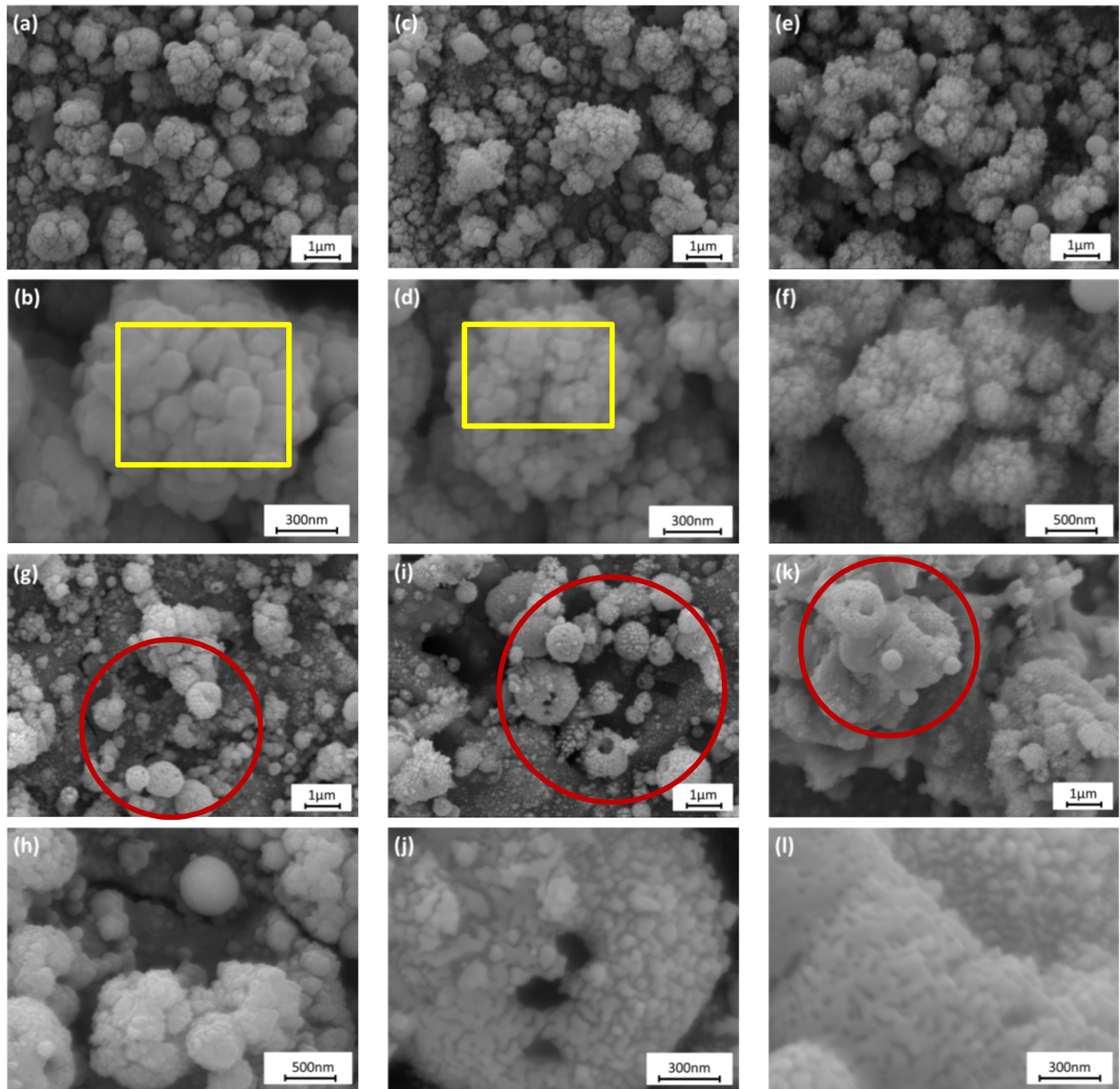

Fig. 75 Surface morphologies of (a, b) P14, (c, d) P12 F12 and (e, f) P11 F11 and (g, h) F14, (i, j)

F12 and (k, l) F11 samples from SPFS route under low and high magnifications. (The yellow rectangles marks the flake nanostructures and red cycle marks the sphere-like particles) 

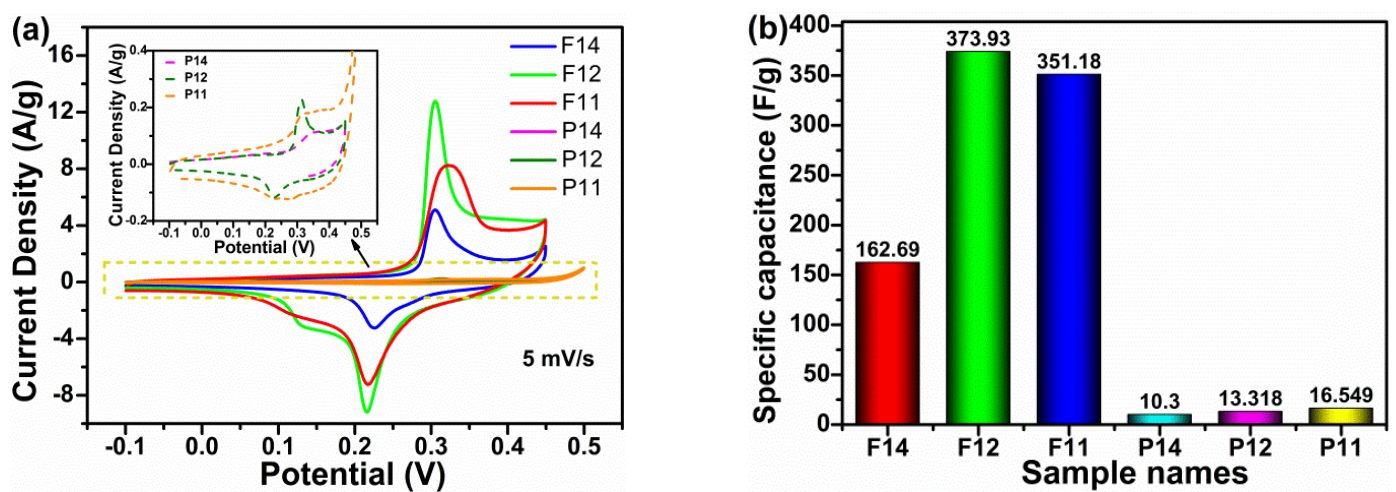

Fig. 76 The electrochemical performance of the electrodes prepared by SPFS and SPPS process with different Ni/Co ratios: (a) Cyclic voltammetry (CV) curves (the insert shows the details of the SPPS electrode CV performance) and (b) calculated specific capacitances.

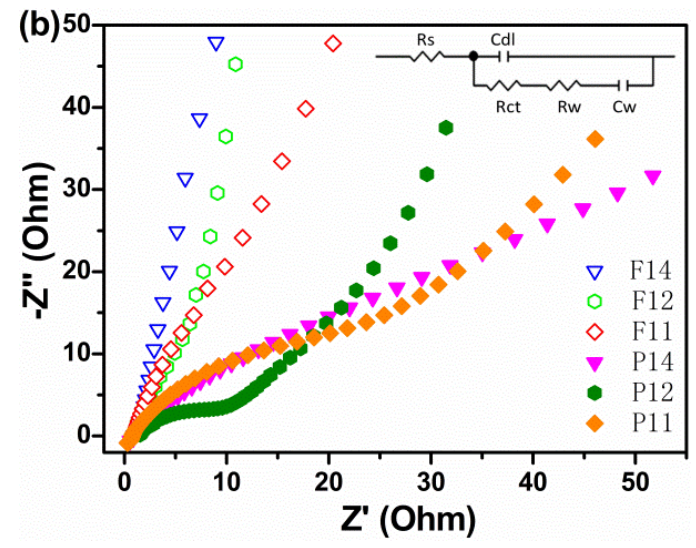

Fig. 87 Nyquist plots of the P14, P12, P11 and F14, F12 and F11 electrodes 

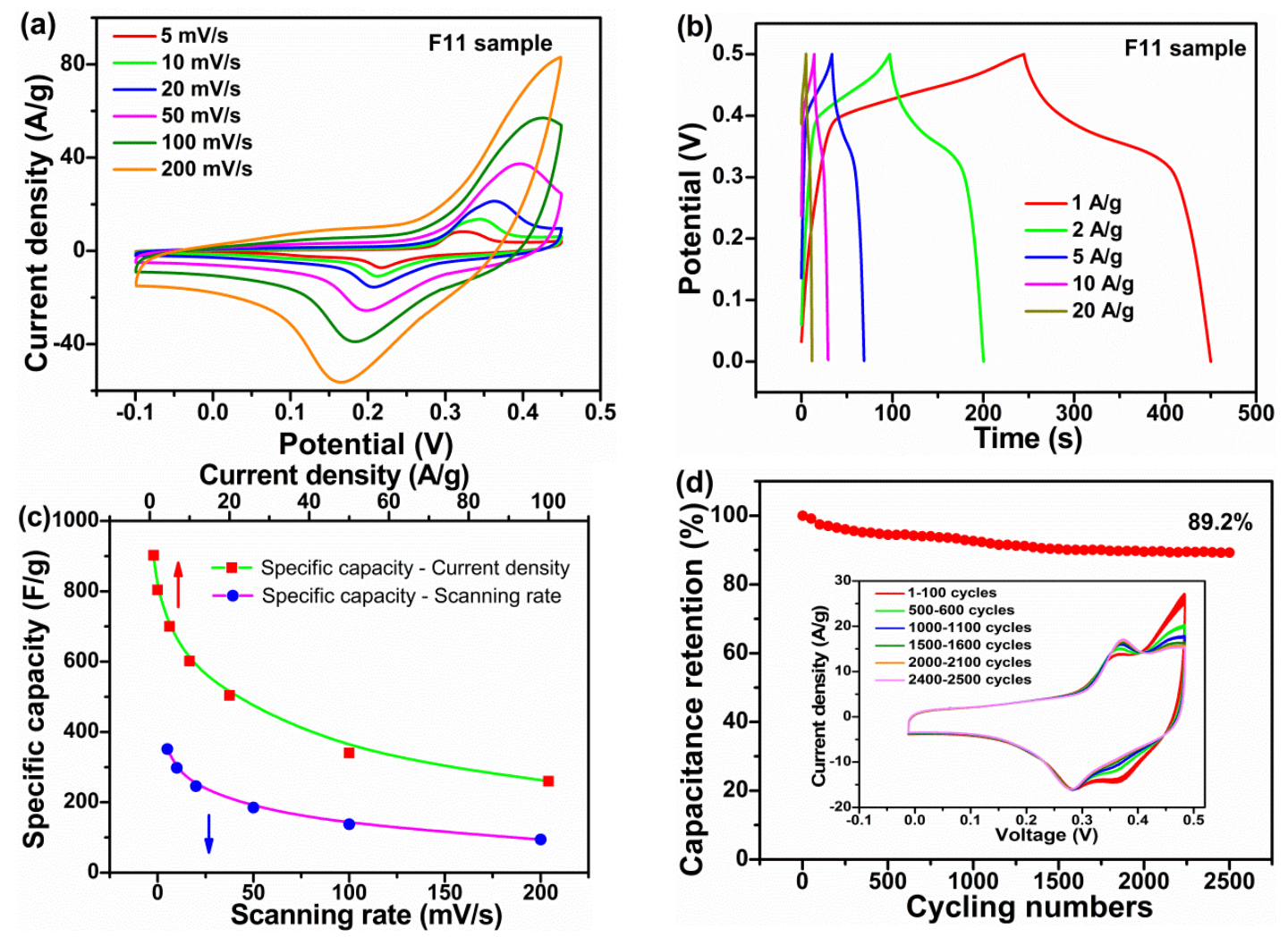

Fig. 98 The electrochemical performance of F11 samples: (a) cyclic voltammetry with different scan rates, (b) galvanostatic discharge-charge with different current densities, (c) specific capacitance decay as a function of different scan rates and current densities, (d) cycle performance of the electrodes during 2500 cycles at the scan rate of $20 \mathrm{mV} / \mathrm{s}$

Table 1 Spraying parameters for the $\mathrm{NiCo}_{2} \mathrm{O}_{4}$ films from different solution ratios via SPPS and SPFS processes

\begin{tabular}{ccccccc}
\hline Sample name & $\mathrm{Ni}\left(\mathrm{NO}_{3}\right)_{2}(\mathrm{M})$ & $\mathrm{Co}\left(\mathrm{NO}_{3}\right)_{2}(\mathrm{M})$ & $\begin{array}{c}\text { Torch power } \\
(\mathrm{kW})\end{array}$ & $\begin{array}{c}\mathrm{O}_{2} \\
(\mathrm{bar})\end{array}$ & $\begin{array}{c}\mathrm{C}_{2} \mathrm{H}_{2} \\
(\text { bar })\end{array}$ & $\begin{array}{c}\text { Air } \\
(\text { bar })\end{array}$ \\
\hline $\mathrm{P} 14$ & 0.04 & 0.16 & 32 & $/$ & $/$ & $/$ \\
$\mathrm{P} 12$ & 0.08 & 0.16 & 32 & $/$ & $/$ & $/$ \\
$\mathrm{P} 11$ & 0.16 & 0.16 & 32 & $/$ & $/$ & $/$ \\
$\mathrm{F} 14$ & 0.04 & 0.16 & $/$ & 4 & 0.7 & 5 \\
$\mathrm{~F} 12$ & 0.08 & 0.16 & $/$ & 4 & 0.7 & 5 \\
$\mathrm{~F} 11$ & 0.16 & 0.16 & $/$ & 4 & 0.7 & 5 \\
\hline
\end{tabular}


Table 2. Results of the scratch test for six different $\mathrm{NiCo}_{2} \mathrm{O}_{4}$ films

\begin{tabular}{ccc}
\hline Sample name & Critical force $(\mathrm{N})$ & Penetration depth at force of $15 \mathrm{~N}(\mu \mathrm{m})$ \\
\hline F11 & $9.55 \pm 0.24$ & $7.62 \pm 0.59$ \\
F12 & $9.59 \pm 0.23$ & $7.82 \pm 0.54$ \\
F14 & $8.47 \pm 0.80$ & $4.59 \pm 0.41$ \\
P11 & $9.61 \pm 0.29$ & $7.93 \pm 0.62$ \\
P12 & $9.84 \pm 0.31$ & $8.95 \pm 0.15$ \\
P14 & $9.01 \pm 0.14$ & $9.78 \pm 0.60$ \\
\hline
\end{tabular}

Table 23 Summary of specific capacitances from $\mathrm{NiCO}_{2} \mathrm{O}_{4}$ related electrodes

\begin{tabular}{|c|c|c|c|c|}
\hline Morphologies & $\begin{array}{l}\text { Current density } \\
\qquad(\mathrm{A} / \mathrm{g})\end{array}$ & $\begin{array}{c}\text { Specific } \\
\text { capacitance (F/g) }\end{array}$ & Preparation method & Ref \\
\hline Hexagonal Nanoplates & 1 & 294 & Hydrothermal & {$[18]$} \\
\hline Hollow micro-sphere & 1 & 880.4 & Hydrothermal & [57] \\
\hline $\begin{array}{l}\text { Mesoporous hollow sub- } \\
\text { microspheres }\end{array}$ & 1 & 678 & $\begin{array}{l}\text { Template-assisted } \\
\text { synthesis }\end{array}$ & [58] \\
\hline $\begin{array}{l}\text { Dandelion-like } \\
\text { microspheres }\end{array}$ & 1 & 372 & Hydrothermal & [59] \\
\hline Nanoparticles & 1 & 866 & Hydrothermal & {$[60]$} \\
\hline Yolk-shelled spheres & 0.5 & 836 & $\begin{array}{c}\text { A controlled } \\
\text { hydrolysis process }\end{array}$ & [13] \\
\hline $\begin{array}{c}\text { Core-shell } \\
\mathrm{NiCo}_{2} \mathrm{O}_{4} @ \text { PANI } \\
\text { nanorod arrays }\end{array}$ & 1 & 901 & Hydrothermal & {$[61]$} \\
\hline Ultrathin nanobelts & 1 & 759 & Hydrothermal & {$[62]$} \\
\hline Hollow microspheres & 2 & 720 & $\begin{array}{l}\text { Microspheres hard } \\
\text { templates synthesis }\end{array}$ & [12] \\
\hline Hollow microspheres & 1 & 902 & $\begin{array}{l}\text { Solution Precursor } \\
\text { Thermal Spray }\end{array}$ & $\begin{array}{l}\text { This } \\
\text { works }\end{array}$ \\
\hline
\end{tabular}

